\title{
Physical and biological constraints on the capacity for life-history expression of anadromous salmonids: an Eel River, California, case study
}

\author{
Alyssa M. FitzGerald, David A. Boughton, Joshua Fuller, Sara N. John, Benjamin T. Martin, Lee R. Harrison, \\ and Nathan J. Mantua
}

\begin{abstract}
Recovery of anadromous salmonid populations is complicated by their complex life histories. We examined the spatiotemporal interplay of stream temperature, geomorphic features, and a species' thermal sensitivity mediated by biological interactions in a case study of steelhead trout (Oncorhynchus mykiss) and Chinook salmon (Oncorhynchus tshawytscha) in California's Eel River watershed. We estimated habitat suitability and fish capacity for each salmonid run and freshwater life stage during average, cool, and warm years in each of the watershed's subbasins, including a historically occupied highelevation subbasin upstream of an impassable dam. Our estimates varied depending on whether we accounted for exposure to the Sacramento pikeminnow (Ptychocheilus grandis), an introduced predator and competitor. Our results indicate that the dammed subbasin has substantial salmonid capacity relative to the rest of the watershed and could provide an important cool-water refuge during warm years and from pikeminnow, potentially improving the productivity and resilience of multiple anadromous salmonid populations. Our approach can be applied in any setting where spatially explicit habitat metrics can be estimated and population-specific and life-stage-specific habitat criteria can be specified.
\end{abstract}

Résumé : La complexité des cycles biologiques des salmonidés anadromes complique le rétablissement de leurs populations. Nous examinons l'interaction spatiotemporelle de la température du cours d'eau, d'éléments géomorphologiques et de la sensibilité thermique des espèces modulée par les interactions biologiques dans une étude de cas de la truite arc-en-ciel anadrome (Oncorhynchus mykiss) et du saumon chinook (Oncorhynchus tshawytscha) dans le bassin versant de la rivière Eel, en Californie. Nous estimons la qualité des habitats et la capacité de charge de poissons pour les différentes étapes de migration et de vie en eau douce de ces salmonidés durant des années moyennes, froides et chaudes dans chacun des sous-bassins du bassin versant, dont un sous-bassin de haute altitude occupé par le passé situé en amont d'un barrage infranchissable. Nos estimations varient selon que nous tenons compte ou non de l'exposition à la sauvagesse du Sacramento (Ptychocheilus grandis), un prédateur et concurrent introduit. Nos résultats indiquent que le sous-bassin endigué présente une capacité de charge de salmonidés considérable comparativement au reste du bassin versant et pourrait offrir un important refuge d'eau froide durant des années chaudes et contre la sauvagesse, améliorant potentiellement la productivité et la résilience de plusieurs populations de salmonidés anadromes. Notre approche peut s'appliquer à tout contexte où des paramètres spatialement explicites de l'habitat peuvent être estimés et des critères relatifs à l'habitat peuvent être spécifiés pour des populations et étapes du cycle biologique précises. [Traduit par la Rédaction]

\section{Introduction}

Recovery of anadromous salmonid populations is complicated by the fact that these fish have complex life histories, exposing them to a variety of climatic, physical, and biological impacts throughout their life cycle. A useful framework for sorting through this complexity emphasizes how abundance and productivity (i.e., population growth rate), mediated by a population's interactions with habitat via spatial structure and diversity, impact a population's long-term viability (McElhany et al. 2000). Conceptually, the most straightforward way to apply these ideas has been through quantitative life-cycle models that estimate survival across successive life stages under various climatic and hydrologic conditions. But life-cycle models usually require detailed data on stage-specific survival and abundance over many years (e.g., Scheuerell et al. 2006; Zeug et al. 2012; Crozier et al. 2021), which tends to bias their application to highly impacted populations where collection of such data are mandated. To assess recovery scenarios for understudied or extirpated populations, an alternative approach is to

Received 19 August 2021. Accepted 16 November 2021.

A.M. FitzGerald and S.N. John. Fisheries Ecology Division, Southwest Fisheries Science Center, National Marine Fisheries Service, National Oceanic and Atmospheric Administration, 110 McAllister Way, Santa Cruz, CA 95060, USA; Institute of Marine Sciences, University of California, 1156 High St., Santa Cruz, CA 95064, USA.

D.A. Boughton, L.R. Harrison, and N.J. Mantua. Fisheries Ecology Division, Southwest Fisheries Science Center, National Marine Fisheries Service, National Oceanic and Atmospheric Administration, 110 McAllister Way, Santa Cruz, CA 95060, USA.

J. Fuller. NOAA Fisheries West Coast Region, California Coastal Office, US Department of Commerce, 777 Sonoma Ave., Rm. 325, Santa Rosa, CA 95404, USA.

B.T. Martin. Department of Theoretical and Computational Ecology, University of Amsterdam, Sciencepark 904, Amsterdam, the Netherlands.

Corresponding author: Alyssa M. FitzGerald (email: alyssa.fitzgerald@noaa.gov).

() 2021 The Author(s). This work is licensed under a Creative Commons Attribution 4.0 International License (CC BY 4.0), which permits unrestricted use, distribution, and reproduction in any medium, provided the original author(s) and source are credited. 
quantify the capacity of the population's environment. Capacity provides an estimate of the potential abundance of a population and can be accomplished in any setting where spatially and temporally explicit environmental metrics (e.g., monthly temperature, channel gradient) can be estimated and associated criteria (e.g., thermal and gradient thresholds) for populations and life stages can be specified.

This alternative approach of assessing the potential abundance of populations from the environment may be particularly useful to evaluate restoration scenarios and potential reintroductions to formerly occupied habitats (Beechie et al.1994; Pess et al. 2008), a goal of many management action plans (McElhany et al. 2000; NMFS 2013, 2016; PVP NOI Parties 2020a). Providing fish passage and subsequent recovery efforts can be expensive and are only practical if ecosystem recovery, including a significant increase in salmonid abundance or productivity, is anticipated (Bellmore et al. 2019; PVP NOI Parties 2020a, 2020b). The amount of suitable habitat or carrying capacity of fish is often substituted as a proxy for potential abundance (Burnett et al. 2003; Agrawal et al. 2005; Lindley et al. 2006; Pess et al. 2008; Boughton et al. 2022; Cooper et al. 2020). However, while most published studies have focused on physical habitat features such as thermal conditions or geomorphic characteristics, habitat suitability and capacity can also depend on biological interactions (Fausch et al. 1988). In turn, biological interactions such as competition and predation rates may be influenced by physical habitat features. For example, salmonid feeding rates, growth rates, and spatial distributions can be mediated by interspecific competition, and competition can depend on physical features such as temperature and stream gradient (Fausch et al. 1994; Taniguchi et al. 1998; Reese and Harvey 2002; de la Hoz Franco and Budy 2005). Similarly, predation rates on juvenile Chinook salmon (Oncorhynchus tshawytscha) can be influenced by the environment; for example, based on both experimental and field data, warmer temperatures or low light intensity (e.g., at dusk or dawn) can increase predation rates (Petersen and Gadomski 1994; Marine and Cech 2004; Michel et al. 2020). Therefore, to better quantify habitat suitability and capacity as a proxy for potential abundance, there is a need to account for the interplay between the spatial and (or) temporal variability in temperature and geomorphic characteristics, the complexities of salmonid life-history diversity, life-stage-specific thermal sensitivities, and biotic interactions.

In this study, we accounted for this complex interplay in a case study focused on California's Eel River Basin. Historically, the Eel River Basin supported robust and commercially exploited runs of salmon and steelhead trout (Oncorhynchus mykiss), but declines in those populations led to their placement on the federal Endangered Species List and subsequent efforts to recover the populations (US Office of the Federal Register 1999, 2000). Drought and climate change may warm stream temperatures to suboptimal or even lethal levels for cold-water salmonids, further impeding salmonid recovery (Eel River Forum 2016). Warmer stream temperatures may also increase predation by and competition with the non-native Sacramento pikeminnow (Ptychocheilus grandis), a recent arrival to the Basin that thrives in warmer waters (Rieman et al. 1991; Brown and Moyle 1991; Reese and Harvey 2002). These unfavorable climate conditions are predicted to become more frequent and severe throughout the western US because of anthropogenic climate change (Ault 2020; Williams et al. 2020). Cool-water refugia are therefore necessary for salmonid recovery and future resilience, especially those refugia that remain suitably cool throughout warm summers and during prolonged drought periods, conditions that have historically been a normal part of California's climate. Because year-round thermal refugia promote salmonid resiliency, survival, and productivity, it is imperative to explore the spatial and temporal distribution of thermal refugia. In particular, the Upper Mainstem Eel River subbasin (hereinafter, Upper Mainstem), which historically hosted multiple populations of salmonids prior to damming (Bjorkstedt et al. 2005), likely harbors more cool-water refugia during summer than most of the rest of the Eel River Basin because of its relatively higher elevation (Isaak et al. 2017).

A key question addressed here is whether the dammed Upper Mainstem provides a disproportionately large amount of suitable thermal refugia that might protect the productive capacity and resiliency of native salmonids from a warming climate and an introduced warm-water predator and competitor. Although other studies have attempted to quantify the habitat suitability or fish capacity in the Upper Mainstem (e.g., VTN 1982; NMFS 2016; Cooper et al. 2020), our study differs from previous evaluations by (1) quantifying capacity and habitat suitability for multiple salmonid life stages using broad-scale geomorphic features, local habitat characteristics, and thermal criteria based in part on risk of predation and competition posed by Sacramento pikeminnow, (2) assessing how suitability and capacity change throughout a year, (3) comparing suitability and capacity in warm, cool, and average years, and (4) quantifying the value of the blocked subbasin relative to unblocked subbasins in the rest of the Eel River Basin.

\section{Study area}

The Eel River with its tributaries contains $\sim 10000$ total river kilometres on California's north coast, making it California's third largest salmon and steelhead trout watershed behind the Klamath-Trinity and Sacramento-San Joaquin basins. The Eel River Basin is less negatively impacted by dams than other large watersheds in California, with only two major dams blocking upstream passage. Scott Dam, a 41-m tall concrete dam operated as a storage reservoir since its completion in 1922, has completely blocked upstream passage to and inundated former habitat in the Upper Mainstem subbasin. Cape Horn Dam, a 29-m tall dam $20 \mathrm{~km}$ downstream of Scott Dam, built in 1908 as part of a diversion project, allows for fish passage with a fish ladder. These two dams are part of the Potter Valley Hydroelectric Project, Federal Energy Regulatory Committee (FERC) Project No. 77, currently operated by Pacific Gas \& Electric Company (PG\&E) (Eel River Forum 2016). The Potter Valley project is undergoing relicensing in 2022, and removal of Scott Dam and restoring fish passage to the Upper Mainstem is under consideration to increase salmonid productivity and resilience (PVP NOI Parties 2020a, 2020b).

\section{Materials and methods}

\section{Approach}

We combined broad- and local-scale habitat suitability and density-at-capacity estimates to quantify the amount of potentially suitable habitat and capacity for each subbasin in the Eel River Basin for winter-run and summer-run steelhead trout and fall-run Chinook salmon. First, we evaluated the extent to which each subbasin retains suitable thermal and geomorphic salmonid habitat in an average, cool, and warm year. For each reach within each subbasin, we determined (1) if a reach is thermally suitable (FitzGerald et al. 2021) and (2) if a reach has a habitable geomorphic channel type (Montgomery and Buffington 1997). As these two data are sparsely measured throughout the entire Basin, we employed a spatial stream network model to estimate mean monthly stream temperature for every river kilometre in the Basin (FitzGerald et al. 2021), and we used channel gradient from a 10-m digital elevation model to classify geomorphic channel type (Flores et al. 2006) at the same spatial resolution as the stream temperature model. We then calculated the amount (river $\mathrm{km}$ ) of suitable habitat within each subbasin. Because of the complex life-history diversity of salmonids, reach habitat suitability was calculated separately for each life stage of each run based on life-cycle phenology, thermal tolerances, monthly varying temperature, accessibility, and channel type. We also added temperature-mediated pikeminnow interaction criteria for juvenile rearing habitat suitability. Next, we estimated the relative production capacity of each subbasin based on standard 
Fig. 1. Steelhead trout and Chinook salmon populations in the Eel River Basin, California. Populations were defined as historically independent (likely to persist over 100-year time-scales) or dependent (likely to be extirpated within 100 years without influx from other populations; Bjorkstedt et al. 2005; Spence et al. 2008). The Upper Mainstem Eel subbasin (population 1, dark blue in figure) is currently inaccessible to anadromous salmonids due to Scott Dam. Maps are in geographic coordinate system North_American_1983. [Colour online.]

Steelhead - Winter-run

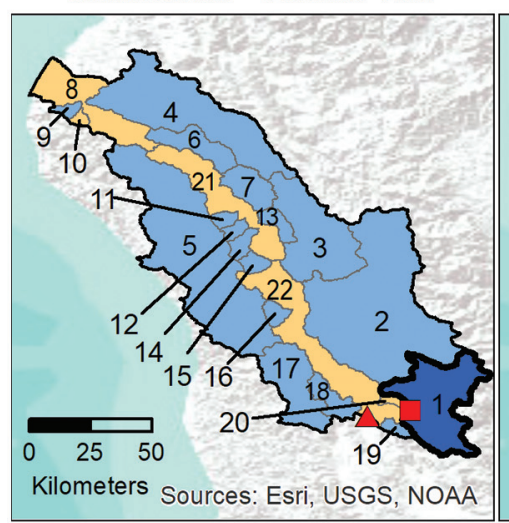

HISTORICAL STATUS

\begin{tabular}{|c|c|}
\hline & Dependent \\
\hline & Independent \\
\hline & $\begin{array}{l}\text { Independent } \\
\text { (currently blocked) }\end{array}$ \\
\hline & DAMS \\
\hline$\Delta$ & Van Arsdale Dam (passable) \\
\hline$\square$ & Scott Dam (impassable) \\
\hline
\end{tabular}

Steelhead - Summer-run

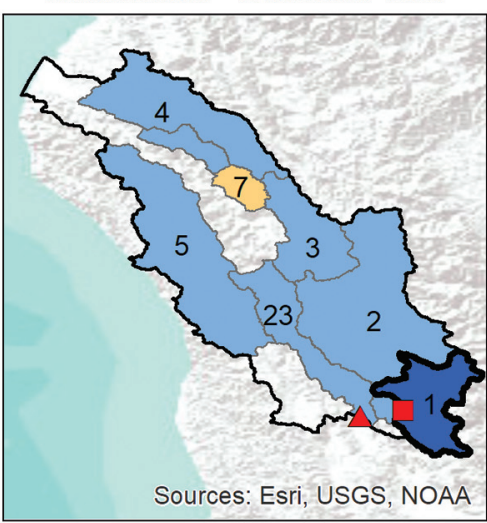

\section{Chinook - Fall-run}

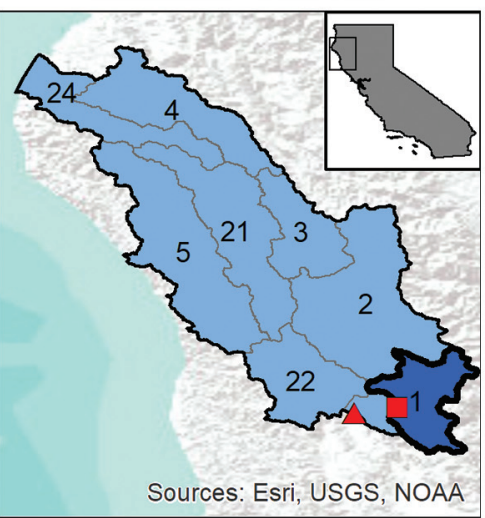

POPULATION

$\begin{array}{lll}\text { 1. Upper Main. Eel } & \text { 9. Price } & \text { 17. Outlet } \\ \text { 2. Middle Fork Eel } & \text { 10. Howe } & \text { 18. Tomki } \\ \text { 3. North Fork Eel } & \text { 11. Jewett } & \text { 19. Bucknell } \\ \text { 4. Van Duzen } & \text { 12. Pipe } & \text { 20. Soda } \\ \text { 5. South Fork Eel } & \text { 13. Kekawaka } & \text { 21. Lower Midd. Main. Eel } \\ \text { 6. Larabee } & \text { 14. Chamise } & \text { 22. Upper Midd. Main. Eel } \\ \text { 7. Dobbyn } & \text { 15. Bell Springs } & \text { 23. Upper Midd. Main. } \\ \text { 8. Lower Main. Eel } & \text { 16. Woodman } & \text { 24. Lower Eel }\end{array}$

juvenile-rearing and adult-spawning densities adjusted for local stream conditions (Cooper et al. 2020). Finally, we determined the latest month that juveniles could leave each subbasin and outmigrate in thermally tolerable conditions to the ocean. We used these results to determine the potential value for anadromous salmonids in the Eel River Basin if the Upper Mainstem was accessible (e.g., via dam removal or fish passage; PVP NOI Parties $2020 a, 2020 b$ ). Below we detail each of the datasets and approaches used in our analysis.

\section{Habitat suitability datasets}

\section{Potentially accessible streams for salmonids}

We defined the potential spatial distribution for each run and life stage from historical population boundaries, accessibility of reaches, and channel type. First, historical population boundaries were defined from a study on salmonid biogeographic breaks that showed that steelhead trout and Chinook salmon in the Eel River Basin are divided into historical populations that generally reflect watershed subbasins (Fig. 1; Bjorkstedt et al. 2005; Spence et al. 2008). Unless otherwise specified, all river or stream names refer to these subbasins rather than individual rivers or streams. We did not analyze any subbasins that were historically uninhabited for a given run. Next, we removed reaches beyond the limits of anadromy for each species. Anadromous limits were defined as upstream of physical impassable barriers (e.g., large waterfalls) or upstream of species-specific barriers inferred from stream gradient as delineated by Spence et al. (2008). One natural cascade in particular, Bloody Rock Roughs in the Upper Mainstem, has been debated as a full or partial barrier to anadromy (VTN 1982; NMFS 2016; Cooper et al. 2020). For this study, reaches upstream of Bloody Rock roughs were classified as inaccessible for Chinook salmon and potentially accessible for steelhead trout, but note that drought may prevent migration for all salmonids (Cooper et al. 2020). We excluded the currently impassable Scott Dam. However, some habitat in the Upper Mainstem subbasin is downstream of Scott Dam and accessible to salmonids, and so we evaluated the habitat upstream (labeled as "Upper Mainstem") and downstream (labeled as "Upper Mainstem_ds") of Scott Dam separately. The NMFS regional California Coastal Office provided their most updated file of physical barriers, and a $10 \mathrm{~m}$ digital elevation model(DEM) provided gradient.

\section{Stream temperature}

Mean monthly stream temperature for each reach was obtained from FitzGerald et al. (2021) (Fig. 2A; Supplemental Fig. S1 $1^{1}$ ). Briefly, FitzGerald et al. (2021) predicted stream temperature using a spatial stream network (SSN) model (Isaak et al. 2017), a specialized statistical regression model that accounts for spatial autocorrelation in temperatures due to stream-network structure and geographic proximity (Peterson and Ver Hoef 2010; Ver Hoef and Peterson 2010; Isaak et al. 2014, 2017). The SSN model was applied to the National Stream Internet (NSI) network (Nagel et al. 2015) at a $1 \mathrm{~km}$ reach resolution for every month of the year. The model was fit with empirical stream temperature from 1993-2015 for the entire KlamathNorthern California region, which includes the stream systems of Eel, Trinity, and Klamath rivers. The model accurately predicted water temperatures in the Klamath-Northern California region, with an average $r^{2}$ of 0.820 and an average mean absolute prediction error of $0.705^{\circ} \mathrm{C}$ across all months for the out-of-sample testing dataset (FitzGerald et al. 2021). Additional modeling details can be found in FitzGerald et al. (2021). The model was then used to predict monthly mean stream temperatures for every river kilometre in the Eel River Basin for every year in the study time period. Reaches classified as manmade lakes and reservoirs were removed because

${ }^{1}$ Supplementary data are available with the article at https://doi.org/10.1139/cjfas-2021-0229. 
Fig. 2. Stream temperatures (A) and geomorphic channel types (B) in the Eel River Basin. The Upper Mainstem Eel subbasin, outlined in black, is currently inaccessible to anadromous salmonids. (A) Predicted mean monthly stream temperatures from FitzGerald et al. (2021) are shown here for October (average of 2002-2011). Temperatures for every month can be found in Supplementary Fig. S1 ${ }^{1}$. (B) Geomorphic channel types in the Eel River Basin were predicted from channel gradient and upstream watershed area, using the classification algorithm of Flores et al. (2006). Maps are in geographic coordinate system North_American_1983. [Colour online.]

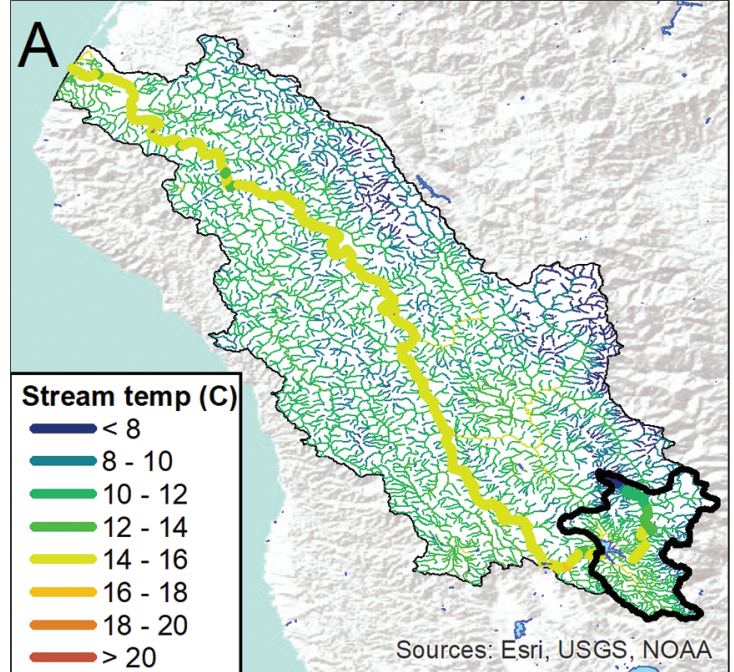

Table 1. Mean monthly temperatures $\left({ }^{\circ} \mathrm{C}\right)$ during an average water year (2002-2011), and the temperature difference $\left({ }^{\circ} \mathrm{C}\right)$ from the average for each month during a cool year (2011) and warm year (2015) in the Eel River Basin.

\begin{tabular}{llllc}
\hline & \multicolumn{2}{l}{$\begin{array}{l}\text { Mean temp. } \\
\left({ }^{\circ} \mathrm{C}\right)\end{array}$} & & \multicolumn{2}{l}{$\begin{array}{l}\text { Temp. deficit }\left({ }^{\circ} \mathrm{C}\right) \text { from } \\
\text { average year }\end{array}$} \\
\cline { 2 - 2 } \cline { 5 - 5 } Month & Average & & Cool & Warm \\
\hline Jan. & 6.00 & & -0.06 & 0.35 \\
Feb. & 6.29 & & -0.82 & 1.69 \\
Mar. & 7.33 & & -0.56 & 1.42 \\
Apr. & 9.07 & & -0.87 & 1.15 \\
May & 11.71 & & -1.33 & 1.33 \\
Jun. & 13.97 & & -1.39 & 2.26 \\
Jul. & 16.92 & & -1.36 & 0.27 \\
Aug. & 16.44 & & -0.19 & 0.23 \\
Sep. & 14.39 & & 0.31 & -0.11 \\
Oct. & 11.11 & & 0.07 & 1.29 \\
Nov. & 7.95 & & -0.53 & -0.63 \\
Dec. & 6.87 & & -0.66 & 0.03 \\
Annual temp. $\left({ }^{\circ} \mathrm{C}\right)$ & $10.67 \pm 4.36$ & $10.05 \pm 4.33$ & $11.44 \pm 4.40$ \\
\hline
\end{tabular}

Note: Annual mean temperature and standard deviation (SD) for each year type are shown in the bottom row.

they involve different thermal dynamics that are not well-represented by the SSN model. The temperature predictions and habitat suitability analyses therefore do not include reaches that are currently inundated (e.g., by Lake Pillsbury, created by Scott Dam). A single river kilometre in the Eel River Basin showed abnormally high predictions (sometimes $>10{ }^{\circ} \mathrm{C}$ higher than the next highest stream temperature in the Basin), and this outlier was removed from all subsequent analyses.

Because water temperature can vary substantially among years, we compared thermal suitability during an average year, an exceptionally warm year, and a cool year. For temperatures during an average year, we took the mean monthly stream temperature from 2002-2011; this time period reflects baseline scenario 2 from Isaak et al. (2017) and includes cool, warm, and average years (Table 1; Supplementary Fig. S2 ${ }^{1}$ ). We used 2011 to represent a cool year

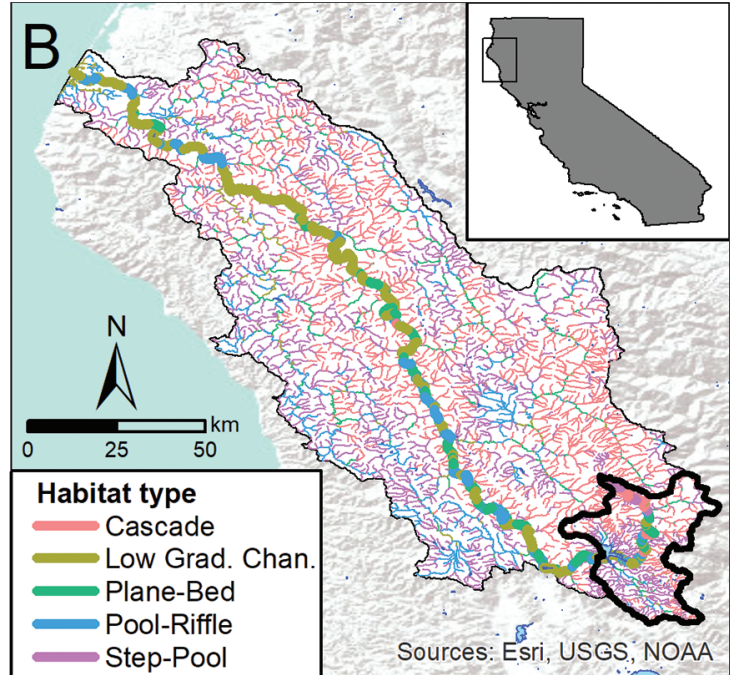

because this year had the lowest annual mean stream temperature in our study period. Even so, two months during that year (September, October) had higher than average temperatures (Table 1). The warm year is represented by 2015, the year with the highest mean annual temperature. Temperatures in June of 2015 were $2.3^{\circ} \mathrm{C}$ above average (Table 1). Additionally, 2015 was an extreme drought year in California.

\section{Geomorphic channel types}

We classified each reach by geomorphic channel type. To do this, we generated a fine-grained hydrography with channel gradients and catchment areas from a $10 \mathrm{~m}$ DEM using the algorithms of Jasiewicz and Metz (2011). We then spatially joined the finer-grained hydrography to the stream network that was used in the temperature modeling, summarizing the mean gradient and catchment area for each $1 \mathrm{~km}$ reach. Then, channel morphology types (Fig. 2B) were assigned using channel gradient and catchment area from a classification tree developed by Flores et al. (2006), where channel types are comparable to the process-based classification system of Montgomery and Buffington (1997). The classification algorithm of Flores et al. (2006) had 76\% accuracy for the stream systems they examined in other parts of the western USA. We added one additional channel type, low-gradient channel, for segments with mean channel gradients less than $0.0003 \mathrm{~m} \cdot \mathrm{m}^{-1}$, which marks the approximate lower range limit of the training data used by Flores et al. (2006) to develop their classification. We expect geomorphology of these segments to vary between meandering and multithread depending on recent history of flooding and land and water use practices and to be dominated by sandy substrates with occasional gravel patches characteristic of episodic flow regimes (e.g., Kondolf and Curry 1986).

\section{Productivity, phenology, and thermal criteria}

We obtained run-specific habitat productivity, phenology, and thermal criteria for each life stage from a review of several published sources. For each life stage of each species, we assigned a qualitative productivity score (ideal, productive, fairly productive, poor) to each channel type based on expert opinion (Table 2). The phenology of each life stage of each run, defined as presence or absence in a month, was obtained from data from the Eel River 
Table 2. Productivity level assumed for different habitat types for several life stages of steelhead trout and Chinook salmon.

\begin{tabular}{|c|c|c|c|c|c|}
\hline \multirow[b]{2}{*}{ Species, life stage } & \multicolumn{5}{|c|}{ Geomorphic habitat types } \\
\hline & Pool-riffle & Step-pool & Plane-bed & Low-gradient channel & Cascade \\
\hline \multicolumn{6}{|l|}{ Steelhead trout } \\
\hline Spawning-incubation-emergence $e^{a, b}$ & Ideal & Productive & Productive & Fairly productive & Poor \\
\hline \multicolumn{6}{|l|}{ Chinook salmon } \\
\hline Spawning-incubation-emergence $e^{b, d}$ & Ideal & Fairly productive & Fairly productive & Fairly productive & Poor \\
\hline
\end{tabular}

Table 3. Phenology for each life stage for winter-run steelhead trout, summer-run steelhead trout, and fall-run Chinook salmon.

\begin{tabular}{|c|c|c|c|c|c|c|c|c|c|c|c|c|}
\hline \multirow[b]{2}{*}{ Life stage } & \multicolumn{12}{|c|}{ Month } \\
\hline & $\mathrm{J}$ & $\mathrm{F}$ & M & A & M & $\mathrm{J}$ & $\mathrm{J}$ & A & $S$ & $\mathrm{O}$ & $\mathrm{N}$ & $\mathrm{D}$ \\
\hline \multicolumn{13}{|c|}{ Eel River winter-run steelhead trout } \\
\hline Adult migration $^{a, b, c, d}$ & $\times x$ & $x \times$ & $\times x$ & $x \times$ & $\times$ & $\times$ & - & - & $\times$ & $\times$ & $\times$ & $\times$ \\
\hline Spawning ${ }^{a, b, c}$ & $x \times$ & $x \times$ & $x \times$ & $x \times$ & - & - & - & - & - & - & $\times$ & $\times$ \\
\hline Adult outmigration ${ }^{b}$ & - & $\times$ & $\times$ & $x$ & $\times$ & $\times$ & - & - & - & - & - & - \\
\hline Incubation $^{e, f}$ & $\times x$ & $\times x$ & $\times x$ & $\times x$ & $x$ & $\times$ & - & - & - & - & $\times$ & $\times$ \\
\hline Juvenile outmigration $^{g, h}$ & - & $\times$ & $\times$ & $\times$ & $\times$ & $\times$ & $\times$ & - & - & - & - & - \\
\hline \multicolumn{13}{|c|}{ Eel River summer-run steelhead trout } \\
\hline Adult migration ${ }^{a, b, c}$ & - & - & $\times$ & $\times x$ & $x \times$ & $\times$ & $\times$ & $\times$ & $\times$ & $\times$ & - & - \\
\hline Holding ${ }^{b, e}$ & $\times$ & - & - & - & - & $\times x$ & $\times x$ & $\times \times$ & $\times x$ & $x \times$ & $\times$ & $x$ \\
\hline Spawning ${ }^{a, e}$ & $x \times$ & $\times$ & $\times$ & $x$ & $x$ & - & - & - & - & - & - & $\times$ \\
\hline Juvenile outmigration $^{g, h}$ & - & $\times$ & $\times$ & $\times$ & $\times$ & $\times$ & $\times$ & - & - & - & - & - \\
\hline \multicolumn{13}{|c|}{ California coastal fall-run Chinook salmon } \\
\hline Adult migration ${ }^{d, e, i, j}$ & $\times$ & - & - & - & - & - & - & - & $x$ & $\times$ & $x \times$ & $x \times$ \\
\hline Holding $^{e, i, j}$ & - & - & - & - & - & - & - & - & - & - & - & - \\
\hline Spawning ${ }^{b, i}$ & $\times$ & $\times$ & - & - & - & - & - & - & - & $x$ & $\times$ & $x \times$ \\
\hline Adult outmigration & NA & NA & NA & NA & NA & NA & NA & NA & NA & NA & NA & NA \\
\hline Incubation $^{e, i, j}$ & $\times$ & $\times$ & $\times$ & $\times$ & $\times$ & - & - & - & - & $\times$ & $\times$ & $\times$ \\
\hline Emergence $e^{e, i, j}$ & $\times$ & $x$ & $\times$ & $\times$ & $\times$ & - & - & - & - & - & - & $x$ \\
\hline Rearing $^{e, i, j}$ & - & $\times$ & $\times$ & $\times$ & $\times$ & $\times$ & $x$ & - & - & - & - & - \\
\hline Juvenile outmigration ${ }^{g}$ & - & - & $x$ & $x$ & $\times$ & $\times$ & $\times$ & - & - & - & - & - \\
\hline
\end{tabular}

Note: Phenology is defined from Eel River Basin steelhead trout populations and from California coastal fall-run Chinook salmon populations. For phenology, “ $\times$ ” indicates presence, and “ $\times \times$ ” indicates peak (if known). A dash (-) may represent no presence or a lack of data. NA is not applicable.

${ }^{a}$ Busby et al. 1996.

${ }^{b}$ J. Fuller, personal observation.

'Puckett 1975.

${ }^{d}$ Kajtaniak and Easterbrook 2019.

${ }^{e}$ Moyle et al. 2017.

${ }^{f}$ McEwan and Jackson 1996.

gVTN 1982.

${ }^{h}$ We did not differentiate between the two steelhead trout runs during juvenile outmigration due to identification difficulty.

${ }^{i}$ Myers et al. 1998.

${ }^{j} \mathrm{NMFS} 2016$.

Basin whenever available (Table 3). For this project, we compared the peak and extended seasons for certain life stages. Peak season indicates when most individuals of that life stage are present, whereas the extended, full season includes all reported months of presence of that life stage.
Thermal thresholds are general criteria not necessarily specific to the Eel River Basin (Table 4). We refer to thermal suitability as "optimal" (the temperatures at which performance is maximized), "tolerable" (any temperature below the upper thermal limit), or "intolerable" (the temperature above which significant mortality 
Table 4. Temperature thresholds of each life stage for steelhead trout and Chinook salmon, based on literature reviews.

\begin{tabular}{|c|c|c|c|c|}
\hline \multirow[b]{2}{*}{ Life stage } & \multicolumn{4}{|c|}{ Thermal threshold $\left({ }^{\circ} \mathrm{C}\right)$} \\
\hline & Tolerable & Optimal & Tolerable & Intolerable \\
\hline \multicolumn{5}{|l|}{ Steelhead trout } \\
\hline Adult migration $^{a, b}$ & $<10$ & $10-15$ & $15-19$ & $>19$ \\
\hline Holding ${ }^{a, c, d}$ & $<10$ & $10-16$ & $16-23$ & $>23$ \\
\hline Spawning $^{a, b}$ & $<6$ & $6-11$ & $11-15$ & $>15$ \\
\hline Adult outmigration & - & - & - & - \\
\hline Incubation $^{a, b}$ & $<6$ & $6-11$ & $11-15$ & $>15$ \\
\hline Emergence $^{b, e}$ & $<8.9$ & $8.9-11.1$ & $11.1-15$ & $>15$ \\
\hline Rearing $^{a, b, f}$ & $<10$ & $10-17^{\mathrm{g}}$ & $17-23^{g}$ & $>23$ \\
\hline Parr outmigration $^{h}$ & - & $<17$ & $17-26.5$ & $>26.5$ \\
\hline Smolt outmigration $^{b, h, i}$ & - & $6-16$ & $16-20$ & $>20$ \\
\hline \multicolumn{5}{|l|}{ Chinook salmon } \\
\hline Adult migration ${ }^{a}$ & $<10$ & $10-20$ & $20-21$ & $>21$ \\
\hline Holding $^{a}$ & $<10$ & $10-16$ & $16-21$ & $>21$ \\
\hline Spawning $^{a}$ & $<13$ & $13-16$ & $16-19$ & $>19$ \\
\hline Adult outmigration & NA & NA & NA & NA \\
\hline Incubation $^{a}$ & $<9$ & $9-13$ & $13-17$ & $>17$ \\
\hline Emergence $^{a}$ & - & - & - & - \\
\hline Rearing $^{a}$ & $<13$ & $13-20^{g}$ & $20-24^{g}$ & $>24$ \\
\hline Juvenile outmigration ${ }^{h, i, j}$ & $<15$ & $15-20$ & $20-24$ & $>24$ \\
\hline Smoltification $^{a}$ & $<10$ & $10-19$ & $19-24$ & $>24$ \\
\hline
\end{tabular}

Note: "Optimal" is the temperature at which performance (e.g., growth rate) is maximized. "Tolerable" implies that temperature-dependent survival will likely occur but performance is reduced relative to the optimal. "Intolerable" represents the incipient upper lethal temperature, above which significant mortality occurs with prolonged exposure. When sources disagreed, we applied the lowest temperature reported. A dash ( - ) represents a lack of data. NA is not applicable.

${ }^{a}$ Moyle et al. 2017.

${ }^{b}$ J. Fuller, personal observation.

${ }^{c}$ CDFW 2015 in Moyle et al. 2017.

${ }^{d}$ Nielsen et al. 1994.

${ }^{e}$ McEwan and Jackson 1996.

${ }^{f}$ Coates et al. 2002.

${ }^{g}$ The thermal thresholds for rearing juvenile salmonids are additionally affected by the presence of pikeminnow; see text.

${ }^{h}$ Beak Consultants Incorporated 1986.

${ }^{i}$ VTN 1982.

${ }^{j}$ Chinook salmon juvenile outmigrants may include both pre-smolts and smolts (J. Fuller, personal observation).

occurs). We defined thermal tolerance as any temperature below the upper thermal limit, but note that these temperatures may not be optimal and performance may be reduced at some tolerable temperatures. For example, the upper thermal tolerance for steelhead trout juveniles is $23^{\circ} \mathrm{C}$, but optimal growing conditions are $10-17{ }^{\circ} \mathrm{C}$ (Table 4).

We developed an additional thermal criterion for rearing juvenile salmonids, accounting for their exposure to pikeminnow predation and competition. The non-native Sacramento pikeminnow is a major predator and competitor of juvenile salmonids in the Eel River Basin. The species was recently introduced (ca. 1979), and native salmonids have been shown to avoid pikeminnow by shifting their habitat use (Brown and Moyle 1991). Adult pikeminnow prefer temperatures above $\sim 18^{\circ} \mathrm{C}$, increasing the likelihood of predation on and competition with juvenile salmonids above this threshold (Vigg and Burley 1991; Petersen and Ward 1999; Reese and Harvey 2002). Interspecific competition has been found to have a negligible effect on juvenile steelhead trout at temperatures $<18^{\circ} \mathrm{C}$, whereas pikeminnow outcompete juvenile steelhead trout at temperatures $>20{ }^{\circ} \mathrm{C}$ (Reese and Harvey 2002). Thermal effects on interspecific competition between juvenile Chinook salmon and pikeminnow are unknown but are likely similar to steelhead trout. Juvenile salmonids can survive and grow in water temperatures $>18{ }^{\circ} \mathrm{C}$ (e.g., Railsback and Rose 1999; Satterthwaite et al. 2010), but for clarity, we use "high-risk" to refer specifically to thermal conditions that expose fish to pikeminnow predation and competition $\left(>18^{\circ} \mathrm{C}\right)$ and "suboptimal" to refer to thermal conditions that expose fish to direct thermal stress or predation. For example, steelhead trout high-risk conditions overlap with tolerably warm rearing temperatures $\left(17-23{ }^{\circ} \mathrm{C}\right)$, so we refer to $17-23^{\circ} \mathrm{C}$ as "suboptimal". For Chinook salmon, high-risk conditions overlap with optimal $\left(13-20^{\circ} \mathrm{C}\right)$ and tolerable rearing temperatures $\left(20-24^{\circ} \mathrm{C}\right)$, so we refer to $18-24^{\circ} \mathrm{C}$ as "suboptimal".

\section{Estimates of habitat suitability}

We combined the datasets described above to evaluate habitat suitability in average, cool, and warm years for holding adults (summer-run steelhead trout only), incubating embryos, and rearing juveniles for all runs during the time period that each life stage is present. Spawning and incubation are constrained both by channel type and temperature, but we only analyzed incubation because constraints are generally the most stringent for embryos incubating (Tables 2, 4). We first assessed geomorphic and thermal suitability separately for each potentially accessible reach to give a baseline estimate if only one factor was important for suitability. Second, we assessed the total amount of suitable habitat, combining geomorphic and thermal suitability. Third, we evaluated the suitability for juveniles during outmigration when they leave their natal subbasins and outmigrate to the ocean to continue growing to adulthood.

Because outmigrating juveniles need a continuously suitable migration route, we determined the thermal suitability of the most direct pathway between each rearing subbasin and the ocean. Specifically, we classified the downstream migration route as thermally optimal, tolerable, or intolerable for outmigrating steelhead trout smolts or Chinook salmon juveniles for each month in cool, average, and warm years. Classification was based on the least thermally tolerable section of the route; for example, if any part of the outmigration pathway was intolerable during a month, that month was subsequently classified as intolerable, effectively blocking outmigration to the ocean. For steelhead trout, we focused on smolts during outmigration because they are less thermally tolerant than non-smolt juveniles rearing and outmigrating (Table 4). For Chinook salmon, we grouped outmigrating fry, parr, and smolts because juvenile outmigrants in the Eel River Basin may include all of these life stages (J. Fuller, personal observation). Additionally, multiple factors, including temperature, may affect these life stages differently (VTN 1982; Beak Consultants Incorporated 1986; Sturrock et al. 2020), but thermal tolerances for outmigrating Chinook salmon fry vs. parr vs. smolts are not well known.

\section{Estimates of capacity}

To estimate juvenile rearing capacity, we expanded the unit characteristic method (UCM; Cramer and Ackerman 2009a, 2009b), applied by Cooper et al. (2020) to the Upper Mainstem, to all subbasins in the Eel River Basin. The UCM is a capacity model that multiplies baseline fish density by unit area of stream habitat, then adjusts the density by habitat scalar values based on parameters describing local conditions (e.g., cover, depth, $\mathrm{pH}$ ) for each habitat unit type, such as fastwater, flatwater, and pools (Cramer and Ackerman 2009a, 2009b); note that field measurements in the Upper Mainstem (Cooper et al. 2020) followed the above habitat unit classifications rather than the channel type classification system from our geomorphic analyses (Montgomery and Buffington 1997). Fish density is closely tied to channel types (Rosenfeld 2003), and fish of different life stages have specific habitat and thermal requirements (e.g., Hughes 1998; Moyle et al. 2017). Baseline fish densities were from a study calculating the number of juveniles rearing at or near likely capacity in different habitat unit types in 
"ideal" conditions (Johnson et al. 1993). Following Cooper et al. (2020), we added a temperature scalar based on thermal effects on juvenile coho (Oncorhynchus kisutch) density (Cramer et al. 2012), assuming that steelhead trout and Chinook salmon show similar relationships (Cooper et al. 2020). Adapted from Cramer and Ackerman $(2009 a, 2009 b)$ and Cooper et al. (2020), we calculated parr capacity as

$$
\begin{aligned}
& \text { Capacity }_{i}=\sum\left(\text { Area }_{j} \times \text { Den }_{j} \times \text { Chnl }_{i j} \times \text { Dep }_{i j} \times \text { Cover }_{i j}\right. \\
&\left.\times \text { Turb }_{i} \times \text { Drift }_{i} \times \text { Fines }_{i} \times \text { pH }_{i} \times \text { Temp }_{i j}\right)
\end{aligned}
$$

where

$i=$ stream segment, usually $1 \mathrm{~km}$ in length and defined by channel gradient and upstream watershed area (i.e., stream reach category; see below),

$j=$ habitat unit type (i.e., fastwater, flatwater, pools),

\section{Baseline UCM:}

Area $=$ usable area in segment $i$ of habitat unit type $j$, the product of length ${ }_{i}$, wetted width ${ }_{i}$, and proportion of stream segment $i$ comprised of habitat unit type $j$,

Den $=$ standard fish density $\left(\right.$ fish $\left.\cdot \mathrm{m}^{-2}\right)$ for a given species in habitat unit type $j$,

\section{Productivity scalars:}

Chnl = scalar based on wetted width $_{i}$, length $_{i}$ (if applicable), and habitat unit type $j$,

Dep $=$ depth scalar based on depth ${ }_{i}$ and habitat unit type $j$,

Cover $=$ cover scalar based on stream segment $i$ and habitat unit type $j$,

Turb $=$ turbidity scalar based on depth $_{i}$ and turbidity (measured $_{i}$ in NTUs during 2016 summer low flow),

Drift = invertebrate drift scalar, the percentage of reach area in fastwater habitat unit types that produce invertebrates (not well studied so set to 1 ),

Fines $=$ fines scalar based on proportion of substrate in riffles of stream segment $i$ composed of fines,

$\mathrm{pH}=\mathrm{pH}$ scalar based on $\mathrm{pH}$ of stream segment $i$,

Temp = temperature scalar, based on temperature of stream segment $i$ and habitat unit type $j$.

In the Eel River Basin, empirical measures of local conditions (excluding stream segment length, stream temperature, and wetted width; see below) were only available for reaches throughout the Upper Mainstem (Cooper et al. 2020). Cooper et al. (2020) categorized each reach surveyed by channel gradient and upstream watershed area and measured habitat characteristics for each reach to estimate the appropriate scalar for local conditions in the Upper Mainstem. Following their approach, we first applied the same reach categorization scheme throughout the Eel River Basin for each stream segment $i$. We then assigned the averaged habitat values by reach category (Cooper et al. 2020) to the appropriate stream segment $i$, given the assumption that habitat scalars measured in the Upper Mainstem could be extrapolated to the rest of the Eel River Basin. Stream segment length and monthly temperature were extracted from our stream temperature modeling.

The absolute capacity of a reach is given by the product of its capacity density (Den) and the reach area (Area), the product of average wetted width and channel length of stream segment $i$. Wetted width measurements from Cooper et al. (2020) were made in the Upper Mainstem from late June to early August during the warmest time of the year at low flow conditions. Steelhead trout rearing occurs throughout the year, such that low flow conditions give an estimate of capacity when the steelhead trout rearing population may be bottlenecked. However, Chinook salmon have usually outmigrated by late spring (VTN 1982; Beak Consultants Incorporated 1986). We therefore modeled wetted width each month to better predict how reach area changes throughout the year, enabling us to better estimate Chinook salmon parr capacity. First, we extracted all available measurements of flow and corresponding wetted widths from USGS stream gages (https://waterdata. usgs.gov/nwis/measurements) within the Eel River Basin from 2002 through 2015 (to match the approximate time-scale of our temperature predictions) and removed any gage with fewer than 20 measurements. For days with multiple observations at a single location, we averaged these observations such that each gage had a single wetted width measurement per day. This totaled to 16 stream gages and 1590 wetted width measurements within the Basin. Stream gage locations were linked with bankfull widths, estimated from upstream watershed area and channel gradient. Wetted width observations were right-skewed, so we log-transformed data prior to modeling. We then fit linear models for each month from observed wetted widths and bankfull widths. Monthly models generally performed well $\left(r^{2}\right.$ range: $\left.0.61-0.84\right)$ and better than an annual model $\left(r^{2}=0.60\right)$, so we used the fitted monthly models to predict wetted width each month throughout the Basin (Supplementary Fig. $S 3^{1}$ ). We did not have enough wetted width measurements to fit models during the cool year $(n=128)$ or warm year $(n=96)$.

The UCM model includes a temperature scalar which is based on temperature and juvenile salmonid density but does not include potential negative effects from the pikeminnow. The magnitude of the effect of pikeminnow on juvenile salmonid density is unknown, but temperatures $>18{ }^{\circ} \mathrm{C}$ are high-risk for juvenile salmonid rearing due to pikeminnow presence. We therefore adjusted all capacity estimates by removing stream segments that were likely conducive to pikeminnow impacts (i.e., $>18^{\circ} \mathrm{C}$ ). We evaluated the effect of pikeminnow on salmonid rearing capacity by comparing these adjusted estimates with the raw, unadjusted estimates calculated by the UCM model.

We first ran the parr capacity model for each subbasin for each month of the year to determine which month most limited rearing capacity for each species. We discuss relative capacity percentages among subbasins because the UCM model includes many assumptions. For example, for the standard densities we used surrogate habitat-specific parr densities from Oregon coastal streams because similar data were not available for the Eel River Basin; see Cooper et al. (2020) for a thorough discussion of UCM model limitations. Then we estimated adult capacity from parr capacity of the bottlenecked month. To estimate the capacity of adults (returning spawners) from parr estimates, we applied several likely parr-toadult recruitment models to obtain a range of realistic estimates. For steelhead trout, we used a $28 \%$ parr-to-smolt recruitment and a $1.5 \%, 13 \%$, or $20 \%$ ocean survival rate (Lister and Walker 1966; Johnson et al. 1993; Quinn 2018; Klein et al. 2008; Rawding et al. 2010; Cramer et al. 2012). For Chinook salmon, we applied a $76 \%$ parr-to-smolt survival rate and $1.5 \%, 3 \%$, or $4 \%$ ocean survival rate (Cramer and Beamesderfer 2006; Quinn 2018; Cramer et al. 2012; Anderson and Ward 2016). We report adult capacity by subbasin based on each potential ocean survival rate.

\section{Results}

Accessibility, thermal suitability, and channel type suitability in the eel river basin

The following results assess accessibility, thermal suitability, and channel type separately. Accessibility values include all potentially occupied reaches, regardless of suitability. Thermal suitability did not account for channel type, and channel type suitability did not account for thermal criteria, allowing us to determine how each factor impacts overall suitability.

In historically occupied subbasins, winter-run steelhead trout could potentially access $5042 \mathrm{~km}$ and summer-run steelhead trout 
Fig. 3. Thermal profiles (A) and total length $(\mathrm{km})$ of each habitat type (B) for potentially accessible reaches in winter-run steelhead trout (top panels), summer-run steelhead trout (middle panels), and fall-run Chinook salmon (bottom panels) subbasins in the Eel River Basin. The currently blocked Upper Mainstem is outlined in red. (A) Each line shows the average temperature of that subbasin throughout an average year (all year types in Supplementary Fig. S4). The box for each life stage shows when that life stage is found in fresh water in the Eel River Basin ( $x$ axis) and the upper thermal tolerance for that life stage ( $y$ axis). To be suitable, the average temperature must be within the box for a specific life stage. The black dotted line shows the lower thermal tolerance $\left(18{ }^{\circ} \mathrm{C}\right)$ for pikeminnow, a major predator and competitor of juvenile salmonids. (B) Total channel lengths $(\mathrm{km})$ predicted for each geomorphic channel type in each subbasin.

[Colour online.]

\section{A Thermal profiles}
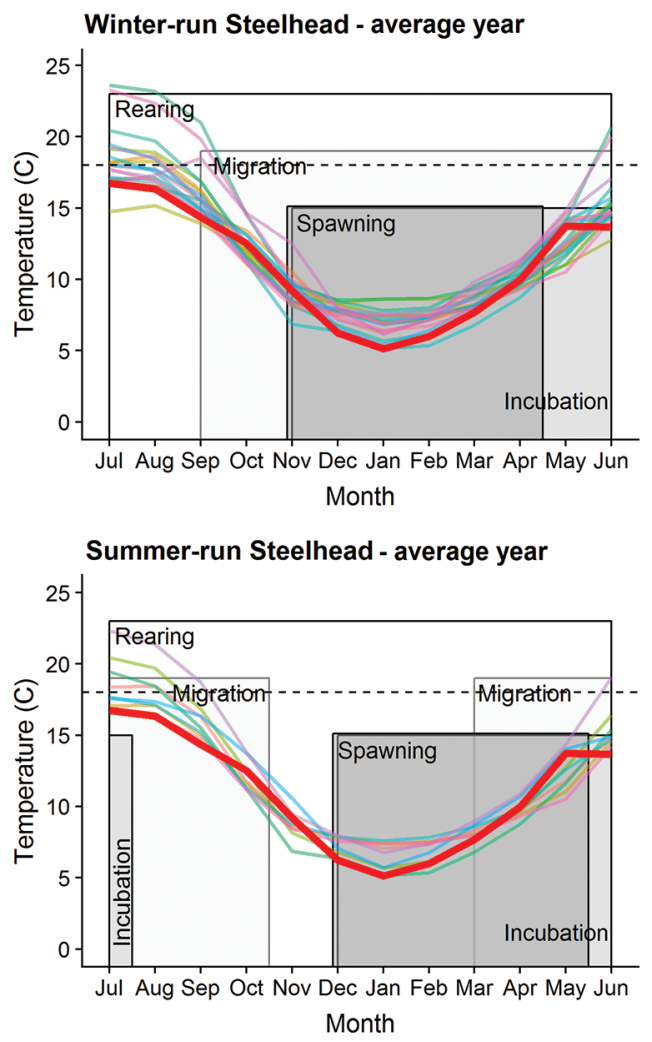

Fall-run Chinook- average year

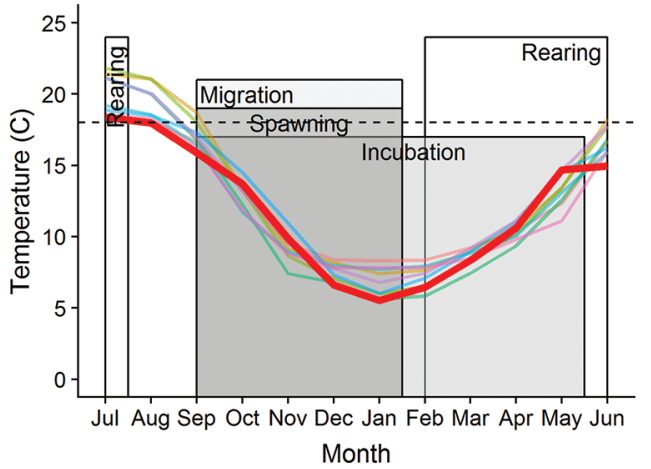

B - Bell Springs

- Bucknell

- Chamise

- Dobbyn

- Howe

- Jewett

- Lower Mainstem Ee

- Lower Middle Mainster

- Lower Middle Mainstem Ee

- Middle Fork Eel

- North Fork Eel

- Outlet

- Pipe

- Soda

- South Fork Eel

- Tomki

- Upper Mainstem Eel_ds

- Upper Middle Mainstem Ee

- Van Duzen

- Woodman

- Upper Mainstem Eel River

- Dobbyn Creek

- Larabee Creek

- Middle Fork Eel

- North Fork Eel

- South Fork Eel

- Upper Mainstem Eel

- Upper Middle Mainstem Ee

- Van Duzen River

- Upper Mainstem Eel River
B Channel types

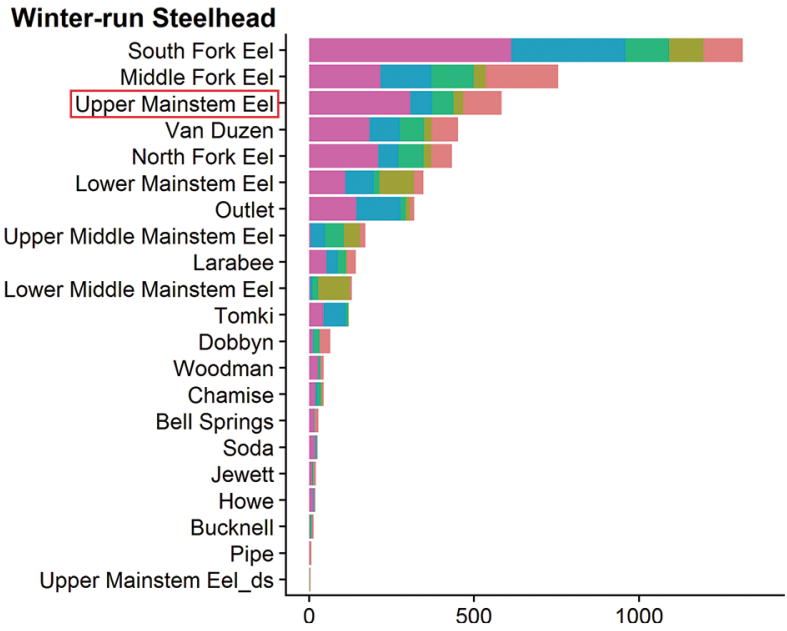

- Lower Eel River

- Lower Middle Eel

- Middle Fork Eel

- North Fork Eel

- South Fork Eel

- Upper Eel River - ds

- Upper Middle Eel

- Van Duzen

- Upper Mainstem Eel River

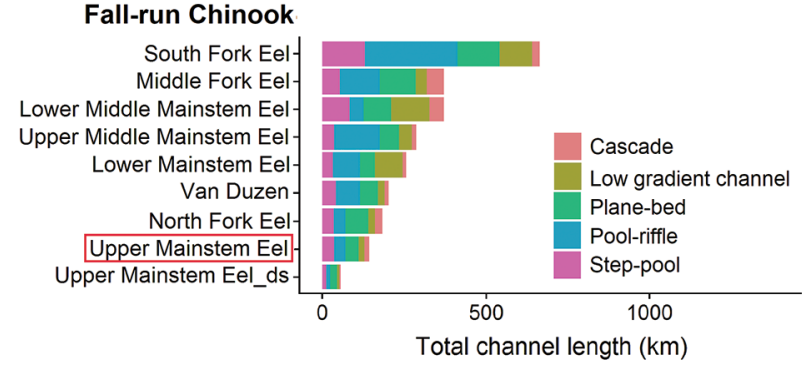

could access $3996 \mathrm{~km}$. Chinook salmon, which have more restrictive physical constraints than and cannot surmount as steep of gradients as steelhead trout, could only access $2538 \mathrm{~km}$. Of the potentially accessible reaches in the Basin, Scott Dam blocks 5.7\% $(144 \mathrm{~km})$ of reaches for fall-run Chinook salmon, $11.6 \%(584 \mathrm{~km})$ for winter-run steelhead trout, and $14.6 \%(584 \mathrm{~km})$ for summer-run steelhead trout.

Monthly temperature exposure of each life stage of each run was usually tolerable or optimal in each subbasin (denoted by height of each life stage box in Fig. 3A). The exception was some steelhead trout subbasins in the summer, which impacted two life stages in particular. First, in some subbasins, late-incubating steelhead trout embryos (incubating into or past May) may have been exposed to intolerable temperatures, especially during warmer than average years ("Incubation" boxes in Fig. 3A; Supplementary Figs. S4, S5A$\mathrm{S}_{5 \mathrm{~B}}{ }^{1}$ ). Similarly, some subbasins were on average thermally tolerable for juveniles, but were high-risk due to increased pikeminnow presence (i.e., $>18{ }^{\circ} \mathrm{C}$; dashed line in Fig. $3 \mathrm{~A}$ ). The Upper Mainstem had cooler temperatures than most other subbasins throughout all months, and across cool, average, and warm years (see thick red lines in Fig. 3A; Supplementary Fig. S4 ${ }^{1}$ ). From August-September 
in each subbasin, temperatures were generally similar between cool, average, and warm years. The biggest temperature differences between year types occurred in the late winter and throughout spring (Supplementary Figs. S4, S5 ${ }^{1}$ ).

The amount (river $\mathrm{km}$ ) and proportion of each channel type varied across subbasins (Fig. 3B) and by life stage. In particular, spawning and incubation are limited by channel type (Table 2), but most of the Basin was geomorphically classified as ideal (i.e., pool-riffle) or productive-fairly productive (i.e., step-pool, planebed, low-gradient channel; Fig. 3B). The Upper Mainstem had a similar high percentage of fair or better spawning and incubation habitat ( $\sim 80 \%-90 \%$, varying by run) relative to the rest of the Basin ( 80\%-93\%), indicating that for these life stages, temperature may be more limiting than channel type. In total, the Upper Mainstem offers 129 and $467 \mathrm{~km}$ (for Chinook salmon and steelhead trout, respectively) of spawning and incubation habitat geomorphically classified as fairly productive or better, comparable to the Van Duzen (190 and $372 \mathrm{~km}$, respectively).

\section{Habitat suitability}

\section{Summary}

In summary, reaches were generally thermally and geomorphically suitable for most of the year, but suitability became restricted throughout the Eel River Basin during summer, and more so in the warm year than in the average year. Rearing juveniles were the most impacted by high temperatures due to thermally mediated exposure to pikeminnow. Other life stages - particularly steelhead trout incubating into the late spring - may have experienced poorer conditions during off-peak season and during a warm year, but conditions during peak season were generally productive. Similarly, high temperatures along the migration route may have prevented juveniles outmigrating in the summer, but most outmigration likely occurred in the spring. In general, the Upper Mainstem had a similar or higher proportion of suitable habitat during all life stages relative to other subbasins. In terms of total habitat, the Upper Mainstem had a comparable amount of consistently suitable habitat as the Van Duzen. Below, we discuss results in detail for each life stage. Unless specifically noted below, habitat suitability results account for both thermal and geomorphic habitat constraints.

\section{Adult migration}

Summer-run steelhead trout usually migrate to the spawning grounds in the spring, whereas fall-run Chinook salmon and winterrun steelhead trout migrate in the late-fall and winter (Table 3). In general for all runs, we found most subbasins during the migration season had tolerable temperatures (Fig. 3A; Supplementary Fig. S4 ${ }^{1}$ ). However, some migrant summer-run steelhead trout may arrive in late spring or summer, and some winter-run steelhead trout and fall-run Chinook salmon may arrive in early fall (Table 3). These early or late migrators could experience intolerably warm temperatures along some reaches (Supplementary Fig. $\mathrm{S5}^{1}$ ). Although thermal conditions for off-peak migrants were usually tolerable in the Upper Mainstem even during the warm year, migrants may have to traverse downstream sections that were intolerable. We did not evaluate channel type because we assume adult migrants can traverse all channel types.

\section{Adult holding}

Summer-run steelhead trout, unlike winter-run steelhead trout and fall-run Chinook salmon, migrate early to the spawning grounds and hold for months prior to spawning in the winter and spring (Table 3). High temperatures in the summer potentially limit their holding distributions, so thermal suitability throughout the Basin was evaluated for June, July, August, and September. We did not evaluate channel type because our geomorphic channel type analysis cannot predict pools formed by exogenous factors like woody debris or rock outcrops (see Discussion). Thermally optimal holding habitat was present in June in most subbasins even during the warm year but became greatly restricted during July and August in all year types (Supplementary Table S1 ${ }^{1}$ ). Still, most reaches in all historic subbasins were tolerable or better across all summer months and year types, with the exception of the Upper Middle Mainstem (Fig. 4; Supplementary Table S1 ${ }^{1}$ ). During the warm year, the Upper Mainstem - alongside Larabee, South Fork, and the Van Duzen - had suitable cold-water habitat for adults holding, but adults would need to pass through other subbasins before those downstream reaches became unsuitable in June or July (Supplementary Table S1 ${ }^{1}$ ); most summer-run steelhead trout adults migrate to upriver holding areas in April and May, although some fish migrate in the summer (Table 3). By September across all year types, all reaches were thermally optimal or tolerable, although stream temperatures were slightly warmer than those in June (Supplementary Table S1 ${ }^{1}$ ). Relative to the rest of the subbasins, the Upper Mainstem had a higher percentage of optimal conditions in August for all year types, second only to the Van Duzen and similar to the South Fork (Fig. 4; Supplementary Table S1 ${ }^{1}$ ). In absolute terms, this translates $216 \mathrm{~km}$ of optimal habitat in the Upper Mainstem, comparable to that of the Van Duzen $(240 \mathrm{~km})$. No reaches in the Upper Mainstem were classified as thermally intolerable during the summer for any year type.

\section{Embryo incubation}

Channel type and thermal suitability varied in peak and extended seasons, by species, and by year type. During peak incubation season for all runs across all year types, the Upper Mainstem had 79\%-90\% suitable habitat (i.e., habitat that was thermally tolerable or better and fairly productive or better), comparable to the Van Duzen subbasin (Supplementary Table S2 ${ }^{1}$ ). Throughout the entire incubation season in cool and average years, the blocked Upper Mainstem had the most (for winter-run steelhead trout) or third most (for summerrun steelhead trout) suitable incubation habitat for steelhead trout runs (Fig. 5; Supplementary Table $S 2^{1}$ ). Steelhead trout had little suitable habitat for the full incubation season during the warm year throughout the Eel River Basin (orange colour in top and middle panels in Fig. 5; Supplementary Table S2 ${ }^{1}$ ). Chinook salmon had suitable incubation habitat throughout the Basin. Notably, Chinook salmon suitability was very similar in peak and extended seasons across year types (bottom panels in Fig. 5; Supplementary Table S2 ${ }^{1}$ ). In contrast, very late steelhead trout spawners and incubating embryos (incubating in or past May) could be exposed to intolerably warm temperatures throughout most of the Basin.

\section{Juvenile rearing and outmigration}

Temperature - either due to physiological constraints or predator-competitor exposure - poses the primary restriction on habitat use for juveniles (Tables 2, 3). Most reaches were suboptimal or tolerable, but several large subbasins (e.g., Middle Fork, Lower Middle Mainstem, Upper Middle Mainstem, North Fork) all had non-negligible amounts of thermally intolerable habitat in July (Fig. 6; Supplementary Fig. S6; Table S3 ${ }^{1}$ ). In contrast, no reaches were intolerable to juveniles in the Upper Mainstem. Still, many reaches were warm enough to expose juveniles to an increased risk of pikeminnow interactions, especially from June-September during all year types. The highest proportions of suboptimal and intolerable conditions occurred in July. Fall-run Chinook salmon in this Basin tend to outmigrate by May (Table 3), avoiding suboptimal or intolerable conditions, whereas steelhead trout rearing occurs throughout the year. The Upper Mainstem hosted a higher amount of optimal rearing habitat for steelhead trout than all other subbasins except the South Fork.

Outmigrating juveniles can use the full range of channel types but need a migration route between their rearing subbasin and 
Fig. 4. Thermal suitability for holding summer-run steelhead trout in the month of August during cool, average, and warm years within the Eel River Basin. (A) The percentage of optimal, tolerable, or intolerable thermal habitat, based on the total amount of accessible habitat, for each summer-run steelhead trout subbasin. Reaches with (B) optimal and (C) tolerable thermal suitability. Reaches suitable during the warm year were also suitable during the average year, and reaches suitable during the average year were also suitable during the cool year. See Fig. 1 for labeled subbasin names. Maps are in geographic coordinate system North_American_1983. [Colour online.]

A

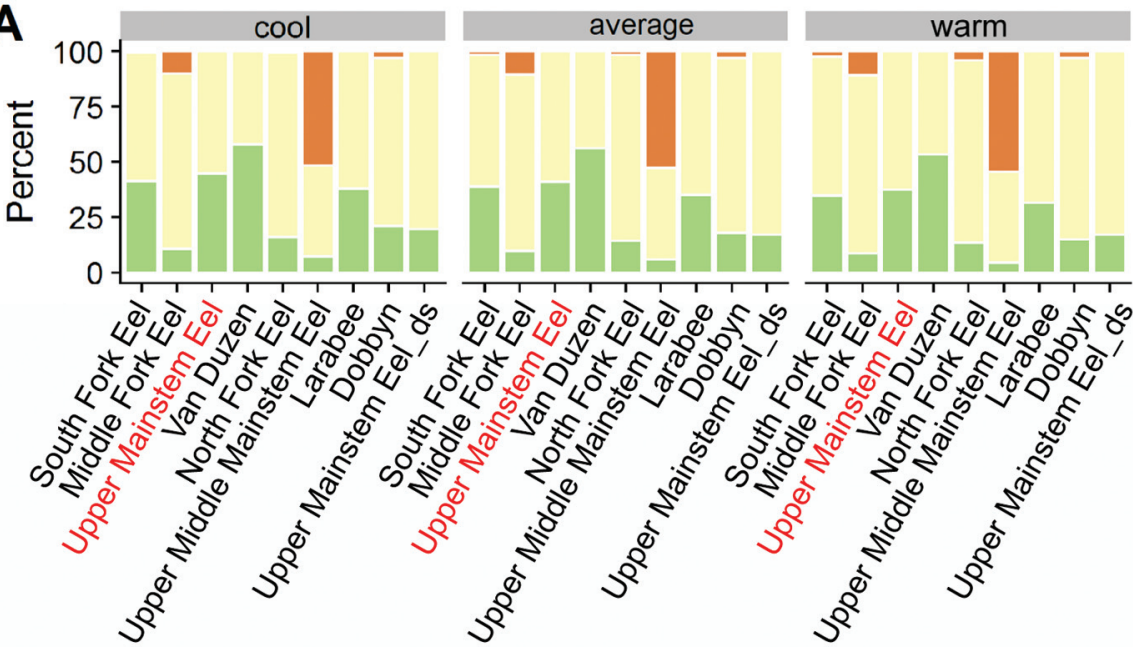

Threshold

Optimal

Tolerable

Intolerable

\section{Subbasin}
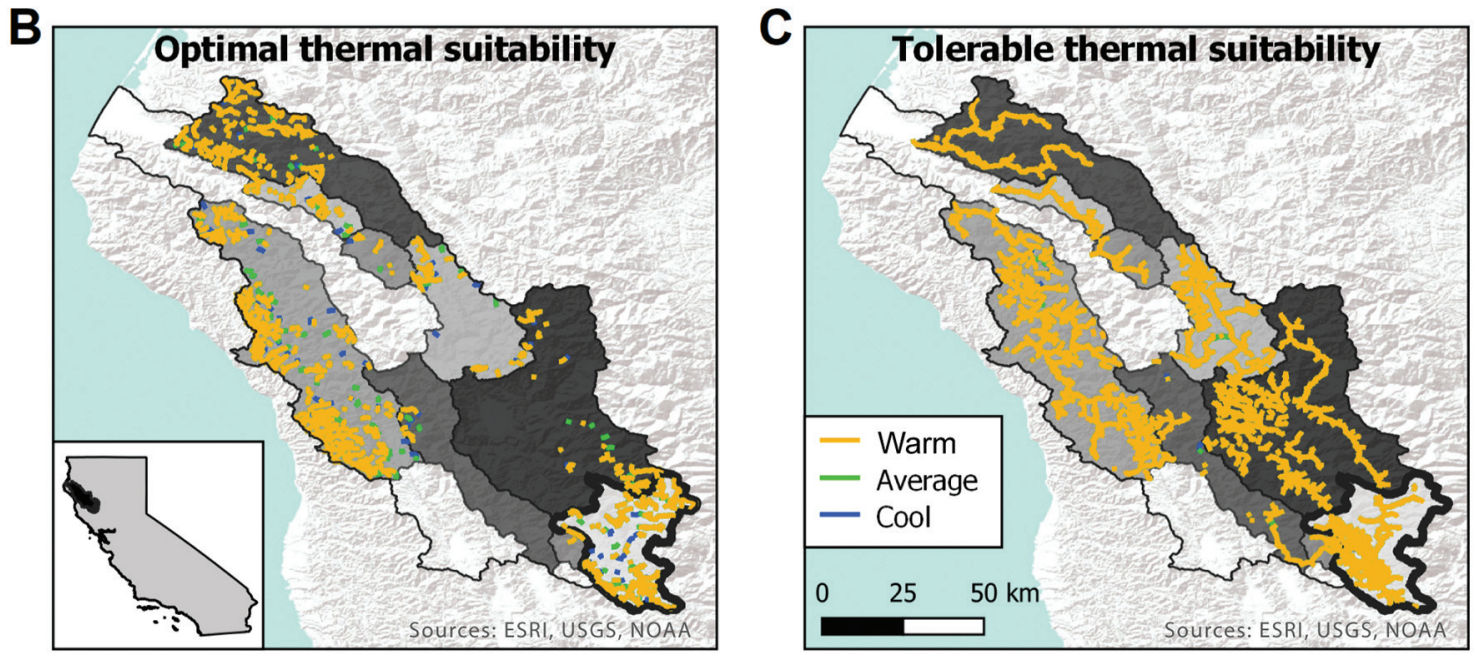

the ocean that is continuously thermally suitable while transiting through it. Generally, we found that all steelhead trout smolt outmigration routes were thermally optimal or tolerable from October through May (Fig. 7A; Supplementary Fig. S7A ${ }^{1}$ ). Intolerable stream temperatures somewhere along most routes prevented steelhead trout smolts from outmigrating in the summer. During the cool year, some relatively short migration routes were tolerable in June compared to intolerable in average years. In the warm year, many relatively long migration routes shifted from optimal (average year) to tolerable in May, and all routes shifted from optimal to tolerable in October. In contrast to steelhead trout smolts, Chinook salmon outmigrants have less stringent thermal limits (Table 4), and juveniles are typically out of rearing areas before mid-summer (VTN 1982; Beak Consultants Incorporated 1986). Still, in the summer, long migration routes were sometimes intolerable, depending on the month and year type (Fig. 7B).

\section{Parr and spawner capacity}

Parr capacity varied across the year due to changes in usable reach area and temperature. Within the steelhead trout rearing

season (full year; Table 3), August was the month most limiting to capacity (Fig. 8A). A few Chinook salmon may rear into July (Table 3), but most outmigration occurs by late spring (VTN 1982; Beak Consultants Incorporated 1986), indicating that May was likely the month with the most limiting capacity for Chinook salmon parr (Fig. 8A). When excluding habitat with pikeminnow exposure, $11.5 \%$ of the steelhead trout parr capacity in the Eel River Basin was found in the Upper Mainstem, similar to the Van Duzen; when pikeminnow exposure was ignored, $5.8 \%$ of capacity was found in the Upper Mainstem, similar to the North Fork. For Chinook salmon, the Upper Mainstem could hold $\sim 1.4 \%$ of the total parr capacity; this value did not change with pikeminnow exposure because temperature throughout the Basin was too cool for pikeminnow in May.

Using three parr-smolt-adult survival models per species, we converted parr capacity in the most limiting month to adult returns (Fig. 8B). In the Upper Mainstem, estimates of adult capacity ranged from 256-5370 for steelhead trout and 1242-3314 for Chinook salmon, with the large ranges in results stemming from (1) the 
Fig. 5. Thermal refuges during the entire extended incubation season that are suitable for winter-run steelhead trout (top), summer-run steelhead trout (middle), or fall-run Chinook salmon (bottom) within the Eel River Basin. Suitability is broken up by year type (colours in legend) and habitat type (left or right panels). In general, reaches suitable during the warm year were also suitable during the average year, and reaches suitable during the average year were also suitable during the cool year. Habitat type designations, months of extended season incubation, and thermal tolerability for incubation for each run can be found in Tables 2-4. Maps are in geographic coordinate system North_American_1983. [Colour online.]

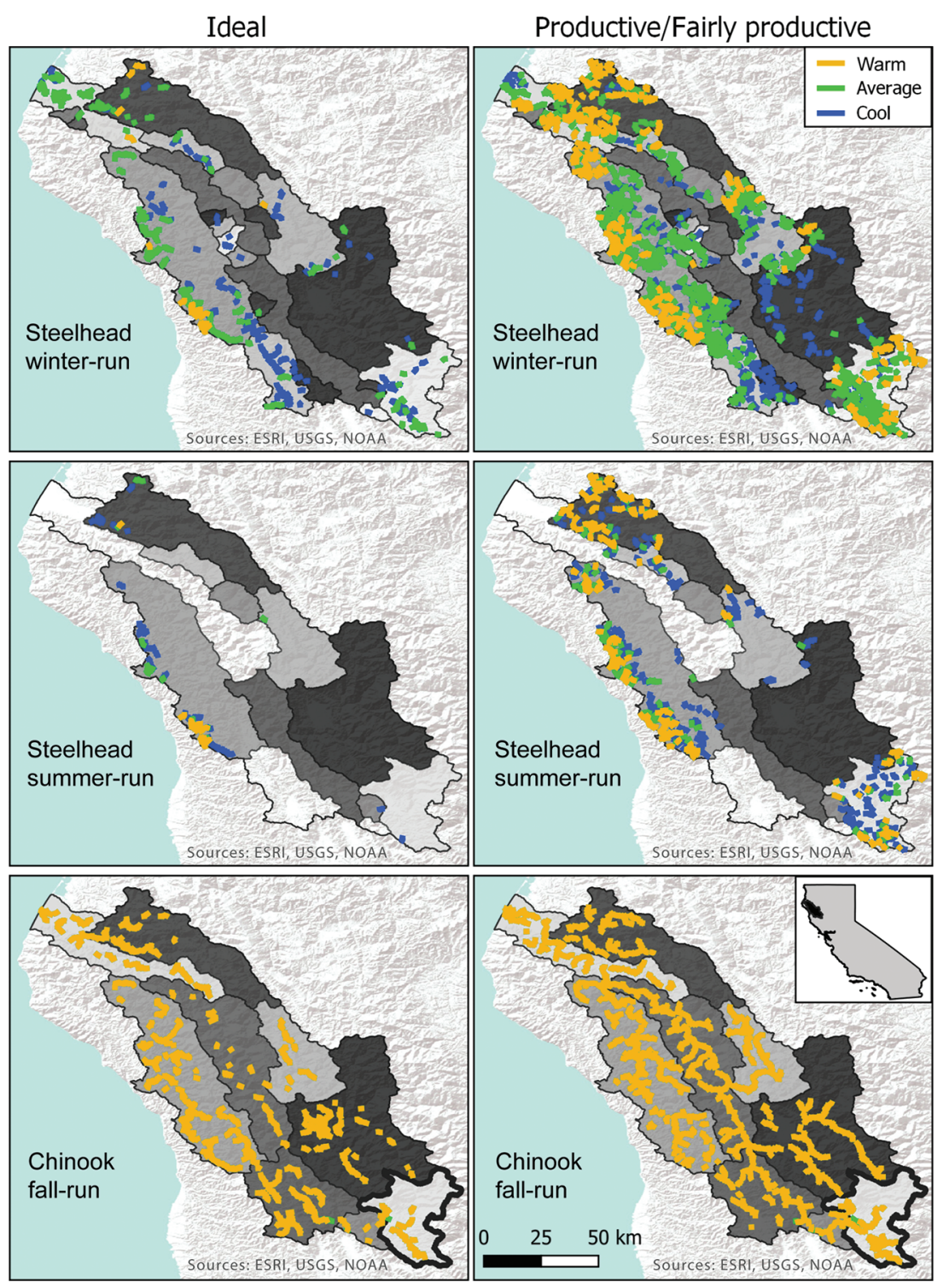

application of three different survival models and (2) whether parr estimates were adjusted for pikeminnow exposure.

\section{Discussion and conclusions}

We compared the habitat suitability and capacity of the Upper Mainstem subbasin that is currently blocked by Scott Dam to all other Eel River subbasins to characterize its relative importance to the Basin's Chinook salmon and steelhead trout populations during cool, average, and warm years. For the Eel River Basin as a whole, our analyses found that most reaches within the limits of anadromy were suitable for the salmonid life stage present in each month, but some reaches became suboptimal due to thermally mediated pikeminnow interactions or even thermally intolerable in the summer months. The amount of suitable habitat was generally higher during the cool year and lower during the warm year relative to the average year, but subbasins showed heterogeneity in how suitability changed by year type. In general, the Van Duzen subbasin had the highest proportion of cool-water refugia and suitable channel type for multiple runs and life stages; the currently inaccessible Upper Mainstem had the second highest proportion of cool-water refugia and suitable channel type of the Eel's subbasins. We found that the Upper Mainstem harbors a significant amount of suitable habitat and could likely sustain anadromous populations of winterrun steelhead trout, summer-run steelhead trout, and fall-run Chinook salmon, even during a warm year. Although we examined suitability and fish capacity in the Eel River Basin, California, our approach can be applied in any setting where spatially explicit environmental metrics can be estimated and habitat criteria for populations and life stages can be specified.

Based on our thermal and geomorphic habitat assessments, the blocked Upper Mainstem generally contains a higher proportion of 
Fig. 6. Thermal quality of juvenile rearing habitat for winter-run steelhead trout, summer-run steelhead trout, and fall-run Chinook salmon subbasins in the Eel River Basin during the summer of cool, average, and warm years. The size of each box represents the total number of potentially accessible river kilometres in that subbasin for each run, shown in the right column. The Upper Mainstem, currently dammed, is highlighted in red. For clarity, only winter-run steelhead trout subbasins with more than 50 river kilometres are shown. All subbasins and all months are shown in Supplementary Fig. S6. ${ }^{1}$ [Colour online.]

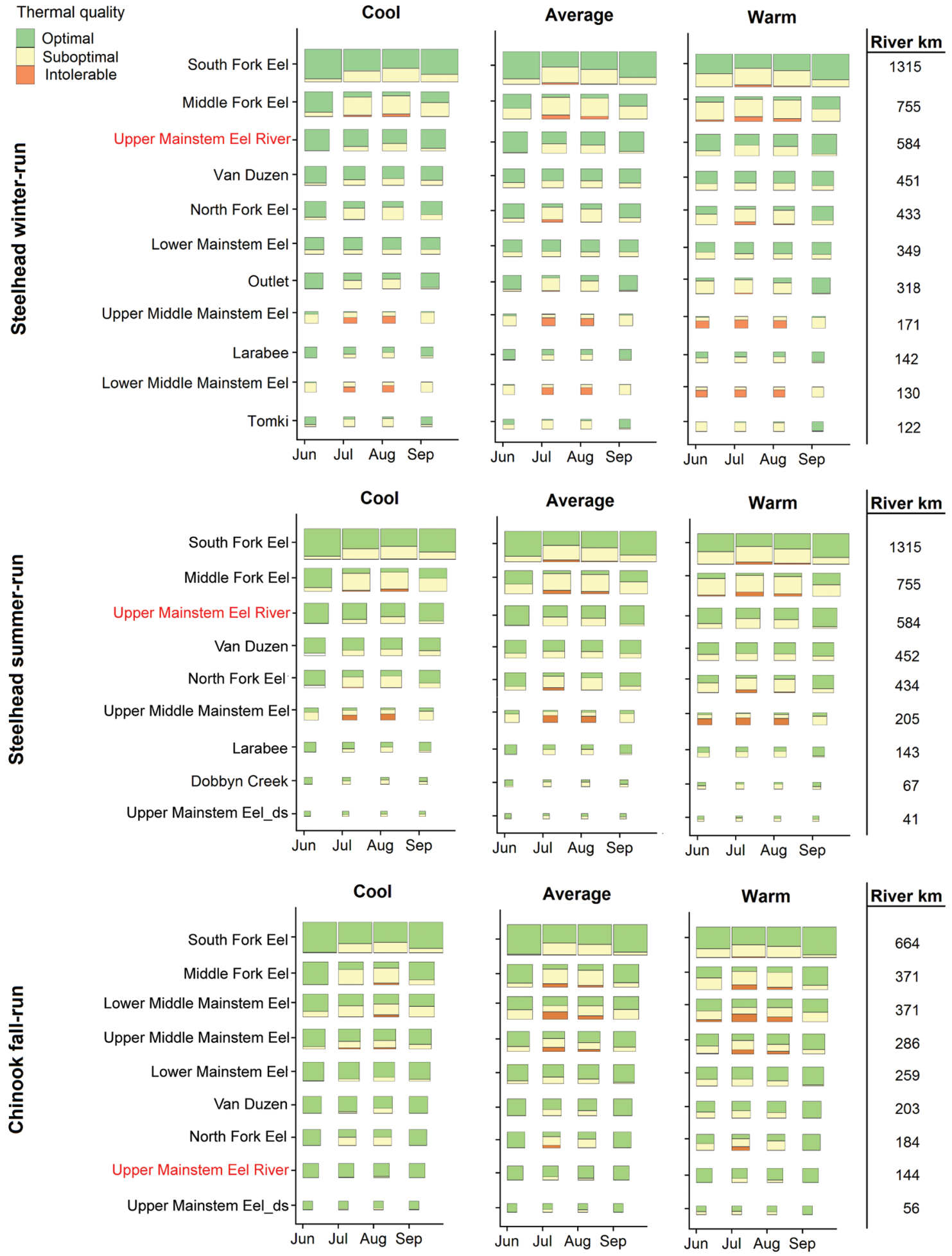

suitable habitat for all freshwater salmonid life stages than much of the rest of the Eel River Basin. Still, suitable habitat was restricted during summers and (or) warm years. During incubation, some reaches became thermally intolerable, particularly for late-spawned

steelhead trout embryos. Similarly, summer-run steelhead trout migrating in the off-peak summer months would likely be exposed to thermally intolerable reaches. However, if migration timing and spawn timing follow a somewhat normal (Gaussian) distribution 
Fig. 7. Thermal suitability of downstream outmigration of (A) steelhead trout smolts and (B) Chinook salmon juveniles. The least suitable section along the route from each subbasin downstream to the ocean defined suitability during each month. The middle panel shows an average year. In the cool (left) and warm (right) year types, suitability that differed from an average year is highlighted with dark shading; suitability with the same classification as an average year has light shading. The usual outmigration timing for each run is outlined in black.

Subbasins are ordered by approximate distance to the ocean (i.e., Upper Mainstem has longest migration route). The Upper Mainstem, currently dammed, is underlined in red. [Colour online.]

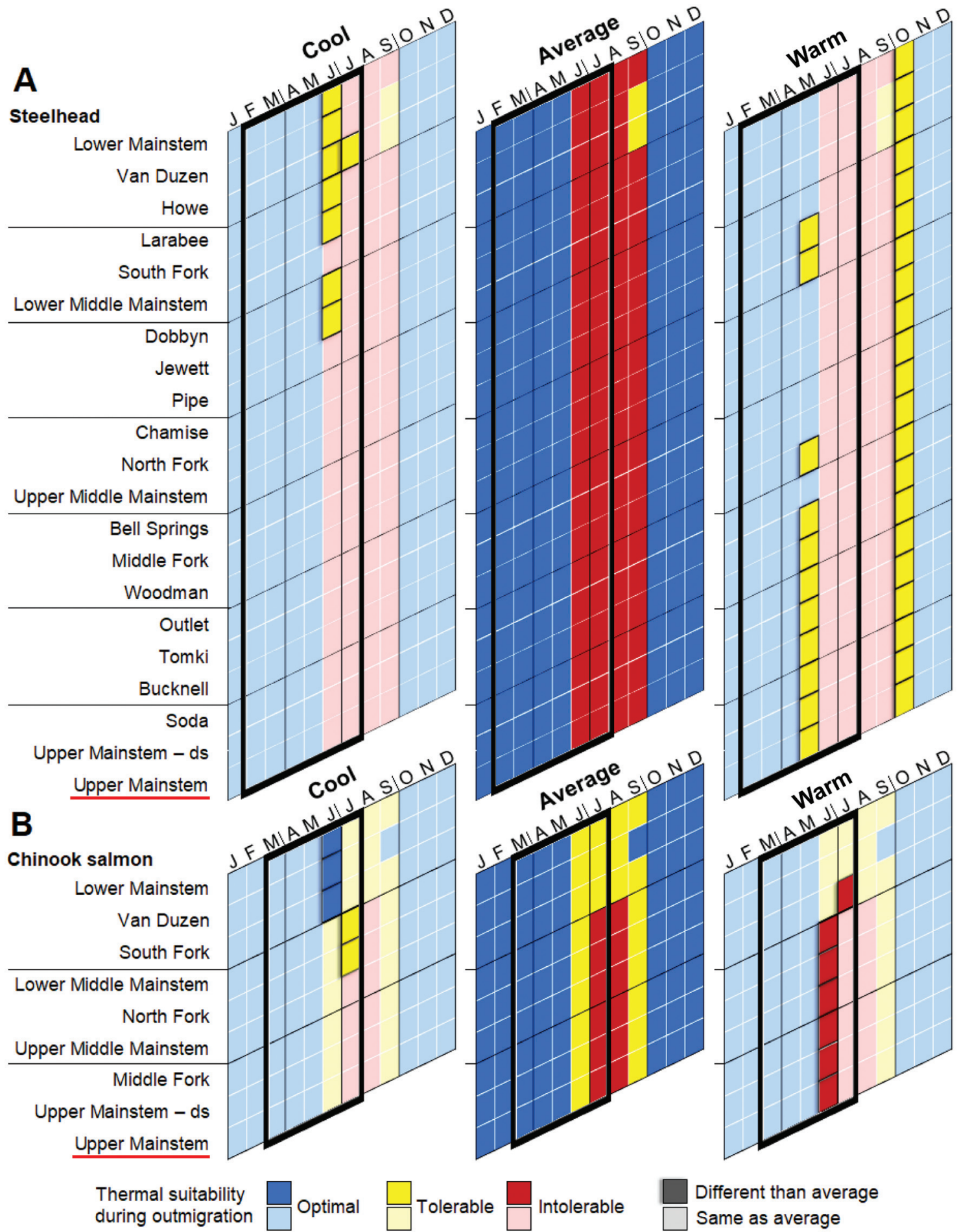

(e.g., FitzGerald et al. 2019), it is likely that relatively little migration or incubation for any run actually occurs during these marginal months surrounding the peak. This means that, on the whole, most migration and incubation was still thermally tolerable, even during the warm year. If water temperatures continue to rise in response to global warming, thermally suitable migration and incubation windows of time may become constricted, effectively constraining the non-peak life history strategies. Fringe, rare, and 
Fig. 8. Estimates of steelhead trout and Chinook salmon capacity in the Eel River Basin. "Adjusted” analyses excluded stream segments conducive to pikeminnow interactions $\left(\geq 18{ }^{\circ} \mathrm{C}\right)$; "raw" analyses included them. (A) Parr capacity $(n)$ by month. Steelhead trout juveniles can rear in fresh water throughout the year, so August is their most limiting rearing month. Most Chinook salmon outmigration occurs by late spring, indicating that May is their most rearing month. (B) Adult spawner capacity (n), calculated from the most limiting month for parr rearing. The coloured bars show estimates based on 13\% (steelhead trout) or 3\% (Chinook salmon) ocean survival rate. The error bars show capacity estimates calculated from high or low ocean survival models. The Upper Mainstem, currently dammed, is underlined in red. For steelhead trout, small subbasins were grouped as "Other". [Colour online.]

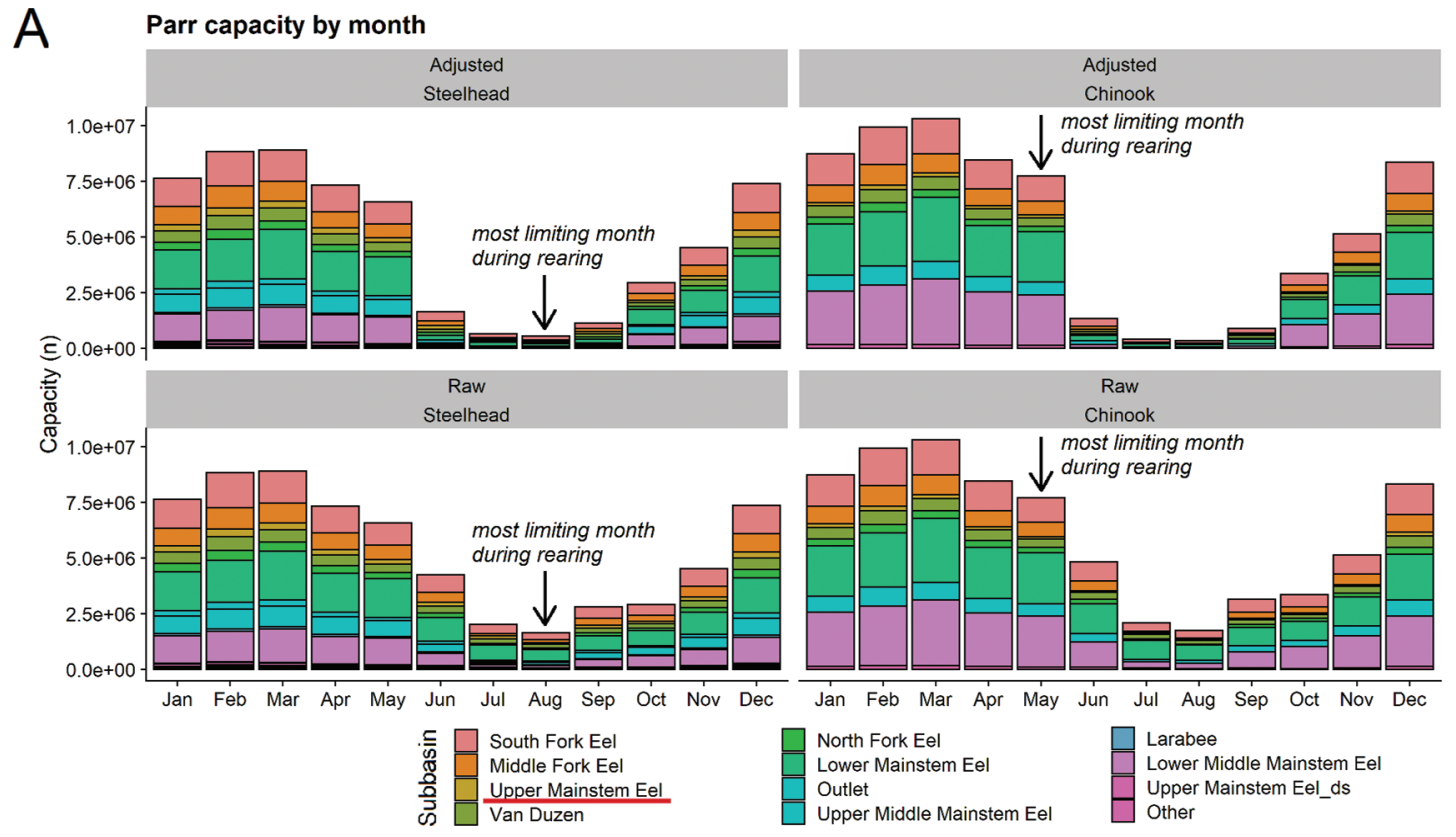

B Steelhead adult capacity

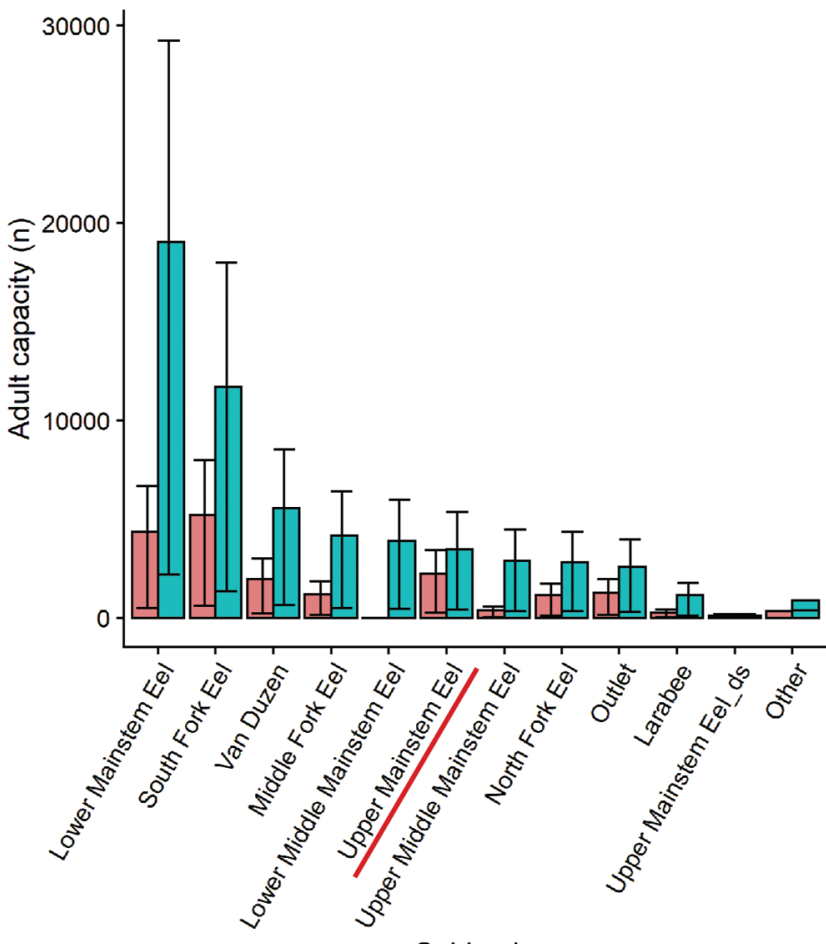

Chinook adult capacity

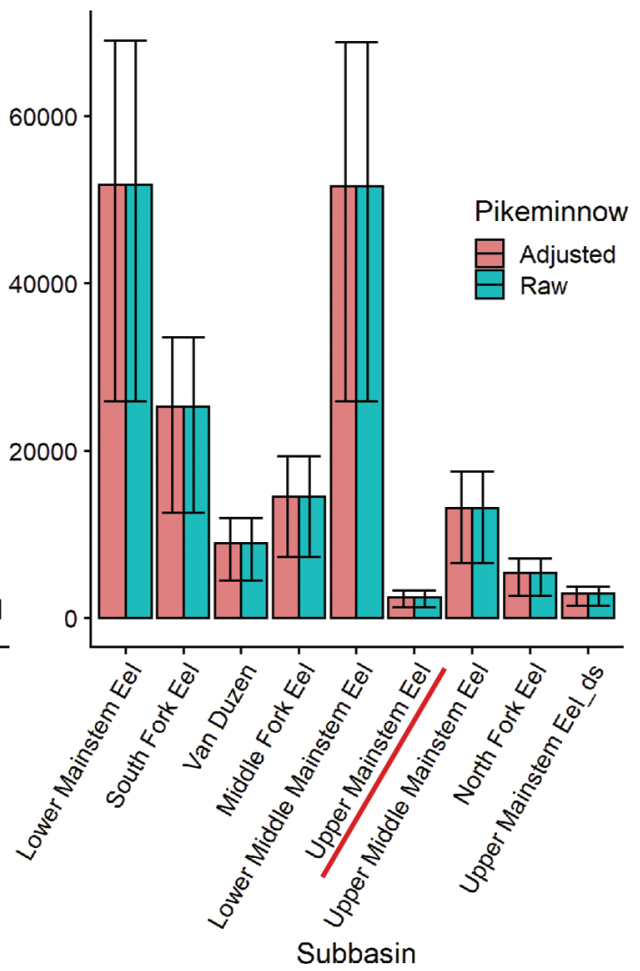

alternative life history strategies can have disproportionate impacts on salmonid abundance and survival during periods of environmental stress (Cordoleani et al. 2021), and within-population diversity is important for salmonid resilience (Greene et al. 2010;
Sturrock et al. 2020). In the Eel River Basin, providing more coolwater refugia in the summer could increase survival for these non-peak life history strategies, helping to increase the resilience of the populations. 
Juvenile rearing was also restricted during summer throughout the Eel River Basin due to the increased exposure to pikeminnow at temperatures above $18{ }^{\circ} \mathrm{C}$. For example, the majority of the Middle Fork, the second largest subbasin, became thermally suboptimal or intolerable in the summer. In contrast, the majority of the Upper Mainstem was thermally optimal during summer months of all year types. This blocked subbasin had a similar amount of thermally optimal habitat $(\mathrm{km})$ as the Van Duzen and Lower Mainstem during July of the warm year, the most limiting case. For steelhead trout, this large amount of optimal rearing habitat was second only to the South Fork subbasin, but the South Fork included reaches with intolerable habitat whereas the Upper Mainstem did not. Therefore, in the summer during warm years, the Upper Mainstem may provide a large amount of cool-water refugia from pikeminnow interactions relative to much of the rest of the Eel River Basin.

We calculated habitat suitability in terms of number of river kilometres, similar to the Intrinsic Potential (IP) model (Burnett et al. 2003). Other models have also estimated the number of suitable river kilometres above Scott Dam, with estimates ranging from $94-463 \mathrm{~km}$ for steelhead trout and $94-160 \mathrm{~km}$ for Chinook salmon (see Cooper et al. 2020 for previous estimates). We estimated that this subbasin (not including potential habitat submerged by Lake Pillsbury) has $169-467 \mathrm{~km}$ for steelhead trout and 51-129 km for Chinook salmon even during a warm year, with results varying by life stage. Our estimate of $461 \mathrm{~km}$ of thermally suitable steelhead trout spawning and incubation habitat in the Upper Mainstem is similar to the $437 \mathrm{~km}$ estimated by Cooper et al. (2020) (neither estimate included reaches inundated by Lake Pillsbury). Although our estimates overlap with others, our assessments are more detailed in that they evaluated the dynamics of suitability across three different year types, included monthly varying stream temperatures and temperature criteria specific to each life stage, and incorporated fish-varying productivity levels in multiple channel types. Additionally, we accounted for an important predator and competitor of salmonids, the pikeminnow, which strongly restricted the amount of suitable habitat for juvenile rearing.

Because our thermal and geomorphic habitat assessments suggest that juvenile rearing is likely the most limiting life stage, particularly for steelhead trout, we assessed adult capacity in each subbasin based on the most limiting month for parr capacity (August for steelhead trout and May for Chinook salmon). Within each species, our adult capacity estimates varied substantially often beyond an order of magnitude - dependent on ocean survival rate scenario and whether we accounted for pikeminnow exposure. Similarly, previous estimates of potential adult capacity above Scott Dam, including those from the IP model (NMFS 2016), a similar UCM model (Cooper et al. 2020), and surrogate data from accessible subbasins (Cooper et al. 2020), have ranged from 1499-26381 for steelhead trout and 1057-10117 for Chinook salmon (see Cooper et al. 2020 for previous estimates). For steelhead trout, our estimates overlap with previous estimates when we included moderate and high ocean survival rate scenarios. Our Chinook salmon adult capacity estimates also overlapped with previous estimates. For Chinook salmon, accounting for pikeminnow exposure did not substantially reduce capacity estimates because May temperatures are relatively cool. In contrast, accounting for steelhead trout exposure to pikeminnow negatively impacted capacity estimates from August. Note, however, that our capacity estimates accounting for pikeminnow interactions treated suboptimal reaches as having no salmonid production, such that true capacity may be higher if pikeminnow reduces rather than eliminates salmonid production. To improve our capacity estimates and reduce their uncertainty for both species, we need the following: a better understanding of pikeminnow impacts on salmonid capacity at different temperatures; ground-truthing throughout the Basin to determine if local conditions measured in the Upper Mainstem are representative of the other subbasins; better estimates or models of wetted width throughout the Basin as flow varies across space and time; more flow and wetted-width measurements in smaller streams; local estimates of parr capacity by habitat unit type; and basin-specific parr-to-adult survival models (Cooper et al. 2020).

All production capacity models, including the UCM model applied here and the IP model, have difficulty in capturing how production and capacity change in dynamic systems. The Eel River Basin is particularly dynamic, containing a variety of channel types with stream temperatures ranging from near freezing to over $25{ }^{\circ} \mathrm{C}$ throughout the year. Reaches that are suitable in average water years may become inaccessible or unsuitable during atypical years due to high temperatures or changes in flow. Spatial heterogeneity of habitat can help mitigate extreme flow and temperature changes because aquatic organisms can use alternate habitat types or thermally tolerable reaches as refuges, increasing the resiliency of the population (Hilborn et al. 2003; Brennan et al. 2019). Further, spatial heterogeneity avoids concentrating vulnerable life stages, particularly juveniles, in areas where mortality risk is higher, for example, due to predation (Nakamoto and Harvey 2003). Heterogeneity also allows organisms to better exploit multiple habitat types during cool years when temperature-dependent mortality is lower (Hilborn et al. 2003; Brennan et al. 2019). For example, early- or late-spawned embryos that would be exposed to intolerable conditions during an average or warm year may instead experience tolerable temperatures during cool years and aboveaverage survival rates, increasing the number of juveniles rearing in those years. To avoid areas of high density and increased competition, juveniles during cool years may exploit non-ideal (but still productive) habitat types. Relative to much of the rest of the Eel River Basin, the blocked Upper Mainstem has a greater proportion of thermally suitable habitat that could be readily exploited, even in summer during a warm year, by both steelhead trout and Chinook salmon. This indicates that the Upper Mainstem could be an important and productive subbasin for the Eel River Basin during abnormally warm years, which are expected to increase in frequency with anthropogenic climate change (e.g., Ault 2020; Williams et al. 2020).

We did not directly estimate the resilience of cool-water refugia in the Eel River Basin to climate change. However, 2015 was an exceptionally warm and dry year that may represent stressful conditions that will occur more frequently in the future in the western US (e.g., Ault 2020; Williams et al. 2020). It is interesting to note that summer-early fall (i.e., July-September) stream temperatures were similar across the cool, average, and warm year cases, indicating that some strong negative feedbacks (e.g., feedbacks stemming from evaporative cooling; Mohseni and Stefan 1999; Boughton et al. 2012) may be limiting peak summer stream temperature. Increased levels of thermal stress for salmonids may instead occur in spring with climate change. In this study, we focused on life stages present in the summer because summer and early fall stream temperatures sometimes were not optimal for these life stages. But if spring stream temperatures warm at a faster rate than summer stream temperatures, life stages present in spring may be more negatively impacted. Still, temperatures were usually well below the thermal thresholds for life stages present in spring, even during the 2015 warm year. However, our work sometimes focused on the upper thermal tolerance limit for each life stage whereas optimal temperatures were often much lower. Additionally, our work used thermal thresholds that were generalized for steelhead trout or Chinook salmon, but populations in the Eel River Basin may have slightly different tolerances.

A lack of knowledge of thermal criteria or other important factors precluded suitability assessments for some life stages in this study. We did not evaluate thermal or geomorphic suitability for post-spawned, outmigrating steelhead trout adults (kelts), emergent embryos of either species, or fall-run adult Chinook salmon staging (i.e., holding for short periods of time downstream of spawning grounds while waiting for suitable conditions), all of which could be negatively impacted by climate change. For outmigrating kelts and emergent embryos, upper thermal limits are 
not well-known. Fall-run Chinook salmon must hold in the estuary in late summer-fall or below spawning grounds if flows are not high enough (Moyle et al. 2017). We did not directly include how changes in flow may affect access to spawning grounds because more flow measurements throughout the Eel River Basin and better models describing how flow varies across space and time are needed. These life stages require further study to determine how flow and temperature variations may affect them in the Eel River Basin.

Two life stages that were included in this analysis may also require further study due to additional factors that could impact habitat suitability during those stages. The first is juvenile outmigration. Our modeling results show when outmigration is either precluded or possible based on stream temperature, but outmigration timing is also influenced by flow conditions, food, rate of stream temperature increase, photoperiod, predation risk, and fish size, each of which could increase mortality if outmigration occurred earlier in the spring or later in the summer (Ewing et al. 1979; VTN 1982; Beakes et al. 2010; Larsen et al. 2010; Sharron 2015; Sturrock et al. 2020). Flow conditions are especially important for outmigrating juveniles, such that water is released from the dammed reservoirs in the spring to try to mimic the historical natural hydrograph and stimulate juvenile salmonid outmigration (NMFS 2002; O'Dowd and Trush 2016). Additionally, outmigration strategy (i.e., smolting instream vs. estuary) and age of smoltification vary among and within populations and years such that outmigration can include fry, parr, and yearling smolts in varying proportions each year. Each of these life-history variants likely has different thermal and other selection pressures (e.g., VTN 1982; Beak Consultants Incorporated 1986; Sturrock et al. 2020), but differences in thermal thresholds are not well-understood. For example, it is possible that predation is size-dependent (e.g., Lorenzen 1996), such that pikeminnow may impact fry or parr more than larger smolts, but this has not been demonstrated, so we did not include a pikeminnow thermal threshold for our outmigration analyses. Future work examining the suitability along juvenile outmigration routes could include other factors such as flow conditions and outmigration timing by fish size.

The second life stage in our study that may require further analysis is adult holding for summer-run steelhead. During the summer, summer-run steelhead trout adults usually hold in slow-moving, cool-water pools, which help them to conserve energy prior to spawning. Our results showed that most reaches were thermally tolerable for adults, and the Upper Mainstem was comparable to the Van Duzen in terms of its amount of optimal holding habitat. Additionally, our prediction of extensive tolerable but little optimal holding habitat in the Middle Fork agrees with a study of empirical temperature recordings of known summer-run steelhead trout holding pools, which found that most pool surface and bottom temperatures were tolerable $\left(16-23^{\circ} \mathrm{C}\right)$ and very few were optimal (A. Clemento, personal communication). Still, our stream temperature modeling assumes water mixing and cannot predict thermal stratification (Isaak et al. 2017). Steelhead trout may be present in stratified layers of pools that are up to $9{ }^{\circ} \mathrm{C}$ cooler than the surface (Nielsen et al. 1994), indicating that there may be more cool-water refugia than our model shows.

An additional consideration is that our adult steelhead trout holding analysis did not include suitability by channel type. Of our geomorphic classifications, self-formed pools are more likely to be found in step-pool or pool-riffle habitats (Montgomery and Buffington 1997; Buffington et al. 2002). Approximately $63.9 \%$ of the currently blocked Upper Mainstem consists of these habitats, and therefore $\sim 373 \mathrm{~km}$ are likely to contain pools, similar to $60.9 \%$ in the other subbasins. However, adult salmonids may also hold in forced pools, which are formed by exogenous factors such as coarse woody debris or streamside rock outcrops. We cannot currently predict forced pools using geomorphic classification alone, although these types of pools may be identifiable using high-resolution aerial imagery or local-scale habitat studies. Our estimates of the amount of suitable habitat for holding adults was therefore based on temperature only. It is important to note that salmonids are more likely to be found in cooler, larger, and deeper pools (Nakamoto 1994; Nielsen et al.1994; Baigún 2003), but we are currently unable to accurately model the likely presence of thermally stratified pools, pool size, or pool depths from geomorphic classifications or stream temperature modeling.

Similarly, our stream temperature model and geomorphic channel type classifications have some limitations regarding spatial scale. Stream temperature was predicted at every river kilometre due to the resolution of the input environmental layers in the model and the regional scale analyzed. However, this spatial scale fails to resolve smaller $(<1 \mathrm{~km})$ cool-water refugia or pools (Fullerton et al. 2018), indicating that more thermally suitable pools may be present than we predict. Previous Eel River Basin studies have modeled stream temperature at finer spatial scales than our study (Asarian and Walker 2016; Asarian et al. 2016; David et al. 2018; Cooper et al. 2020), although these other studies did not predict stream temperature throughout the entire Basin. Regardless, fitting the stream temperature model at finer resolutions may not predict pools that are very deep, thermally stratified, influenced by hyporheic flow, or forced by exogenous factors such as woody debris (Isaak et al. 2017). However, airborne thermal infrared imagery could be used to map surface temperatures at much higher resolution from small planes or unmanned autonomous vehicles (drones) (Fullerton et al. 2018). We predicted geomorphic channel type from gradient and catchment area, estimated from a $10 \mathrm{~m}$ DEM. Although a $10 \mathrm{~m}$ DEM has accurately predicted channel gradient in some systems $\left(r^{2}=0.88\right.$; Davies et al. 2007), a $10 \mathrm{~m}$ DEM may miss finer-scale changes in channel type (Flores et al. 2006). Gradient, catchment area size, and channel type classification accuracy for Eel River subbasins were not assessed here due to lack of training data.

Although there is some inherent uncertainty due to the spatial and temporal scale of our analyses and the large ranges in the number of suitable river kilometres and capacity estimated by our study and others, we conclude that the Upper Mainstem is comparable to the Van Duzen subbasin based on the amount of thermally and geomorphically suitable habitat for multiple freshwater life stages. But there is a potentially more important question: if access was provided to the Upper Mainstem, would these populations rebound? In a similar system, two impassable dams blocking Washington's Elwha River were removed after having been in place for over 100 years. Since their removal, multiple anadromous salmonid populations have recolonized the previously blocked but now accessible upstream Elwha River habitats (Bellmore et al. 2019; McMillan et al. 2019; Fraik et al. 2021). In the Eel River Basin, a recent genetic study showed that steelhead trout with summer-run and winter-run alleles still reside upstream of Scott Dam after 100 years of isolation from other anadromous populations due to lack of upstream passage (Kannry et al. 2020). If access were provided to the Upper Mainstem, these fish have the potential to "restart" the anadromous populations, potentially without additional reintroductions, recolonizations, or translocations from other subbasins (Kannry et al. 2020). Note, however, that to reach the Upper Mainstem, anadromous fish still have to pass Cape Horn Dam via a fish ladder that is only partially compliant with fish passage regulations (Stillwater Sciences et al. 2021); population recovery in the Upper Mainstem may therefore also depend on downstream improvements. Still, based on our evaluation of the quality and quantity of suitable habitat and potential capacity, enabling access to the blocked Upper Mainstem subbasin could likely support populations of winter-run steelhead trout, summer-run steelhead trout, and fall-run Chinook salmon, even during warm months and during exceptionally warm and dry years like 2015. 


\section{Competing interests}

The authors declare there are no competing interests.

\section{Data accessibility}

Relevant data (monthly stream temperature, geomorphic channel type, and monthly wetted width for every stream segment in the Eel River Basin) needed to replicate our work are openly available in the DRYAD data repository at https://doi.org/10.5061/dryad. ksn02v74x.

\section{Acknowledgements}

Funding for this project was provided by NOAA Fisheries West Coast Region California Coastal Office and NOAA Southwest Fisheries Science Center. We thank George Pess and Tim Beechie for providing helpful comments on manuscript drafts. We thank personnel at the NOAA Fisheries West Coast Region California Coastal Office in Santa Rosa for suggestions that helped guide this project in its early stages. Suggestions and comments from two anonymous reviewers greatly improved this manuscript.

\section{References}

Agrawal, A., Schick, R.S., Bjorkstedt, E.P., Szerlong, R.G., Goslin, M.N., Spence, B.C., Williams, T.H., and Burnett, K.M. 2005. Predicting the potential for historical coho, Chinook, and steelhead habitat in northern California. NOAA Technical Memorandum, NOAA-TM-NMFS-SWFSC-379.

Asarian, J.E., and Walker, J.D. 2016. Long-term trends in streamflow and precipitation in Northwest California and Southwest Oregon, 1953-2012. J. Am. Water Resour. Assoc. 52(1): 241-261. doi:10.1111/1752-1688.12381.

Asarian, J.E., Higgins, P., and Trichilo, P. 2016. Stream temperatures in the eel river basin 1980-2015, phase 1: compilation and preliminary analysis. In Prepared by Riverbend Sciences and the Eel River Recovery Project. State Water Resources Control Board, Sacramento, Calif.

Ault, T.R. 2020. On the essentials of drought in a changing climate. Science, 368(6488): 256-260. doi:10.1126/science.aaz5492. PMID:32299944.

Anderson, C.W., and Ward, D. 2016. Results of freshwater creek salmonid life cycle monitoring station 2015-2016. Scientific report prepared in partial fulfillment of Fisheries Restoration Grant No. P1210323, Humboldt State University, Department of Fisheries Biology, Arcata, Calif.

Baigún, C.R. 2003. Characteristics of deep pools used by adult summer steelhead trout in Steamboat Creek, Oregon. N. Am. J. Fish. Manage. 23(4): 1167-1174. doi:10.1577/M02-001.

Beak Consultants Incorporated. 1986. Article 41 studies: To determine the effects of water temperature on downstream migration of anadromous salmonids in the Upper Eel River below Lake Pillsbury. Pacific Gas and Electric Company, San Ramon, Calif.

Beakes, M.P., Satterthwaite, W.H., Collins, E.M., Swank, D.R., Merz, J.E., Titus, R.G., et al. 2010. Smolt transformation in two California steelhead trout populations: effects of temporal variability in growth. Trans. Am. Fish. Soc. 139(5): 1263-1275. doi:10.1577/T09-146.1.

Beechie, T., Beamer, E., and Wasserman, L. 1994. Estimating coho salmon rearing habitat and smolt production losses in a large river basin, and implications for habitat restoration. N. Am. J. Fish. Manage. 14(4): 797-811. doi:10.1577/1548-8675(1994)014<0797:ECSRHA > 2.3.CO;2.

Bellmore, J.R., Pess, G.R., Duda, J.J., O'Connor, J.E., East, A.E., Foley, M.M., et al. 2019. Conceptualizing ecological responses to dam removal: If you remove it, what's to come? BioScience, 69(1): 26-39. doi:10.1093/biosci biy152. PMID:30647476.

Bjorkstedt, E.P., Spence, B.C., Garza, J.C., Hankin, D.G., Fuller, D., Jones, W.E., et al. 2005. An analysis of historical population structure for Evolutionarily Significant Units of Chinook salmon, coho salmon, and steelhead trout in the North-Central California Coast Recovery Domain. NOAA Technical Memorandum, NMFS-SWFSC-382.

Boughton, D.A., Harrison, L.R., John, S.N., Bond, R.M., Nicol, C.L., Legleiter, C.J., and Richardson, R.T. 2022. Capacity of two Sierra Nevada rivers for reintroduction of anadromous salmonids: Insights from a high-resolution view. Trans. Am. Fish. Soc. 151(1): 13-41. doi:10.1002/tafs.10334.

Boughton, D.A., Hatch, C., and Mora, E. 2012. Identifying distinct thermal components of a creek. Water Resour. Res. 48(9). doi:10.1029/2011WR011713.

Brennan, S.R., Schindler, D.E., Cline, T.J., Walsworth, T.E., Buck, G., and Fernandez, D.P. 2019. Shifting habitat mosaics and fish production across river basins. Science. 364(6442): 783-786. doi:10.1126/science.aav4313. PMID:31123135.

Brown, L.R., and Moyle, P.B. 1991. Changes in habitat and microhabitat partitioning within an assemblage of stream fishes in response to predation by Sacramento squawfish (Ptychocheilus grandis). Can. J. Fish. Aquat. Sci. 48(5): 849-856. doi:10.1139/f91-101.
Buffington, J.M., Lisle, T.E., Woodsmith, R.D., and Hilton, S. 2002. Controls on the size and occurrence of pools in coarse-grained forest rivers. River Res. Applic. 18(6): 507-531. doi:10.1002/rra.693.

Buffington, J.M., Montgomery, D.R., and Greenberg, H.M. 2004. Basin-scale availability of salmonid spawning gravel as influenced by channel type and hydraulic roughness in mountain catchments. Can. J. Fish. Aquat. Sci. 61(11): 2085-2096. doi:10.1139/f04-141.

Burnett, K., Reeves, G., Miller, D., Clarke, S., Christiansen, K., and VanceBorland, K. 2003. A first step toward broad-scale identification of freshwater protected areas for Pacific salmon and trout in Oregon, USA. Aquatic protected areas: what works best and how do we know, 144-154.

Busby, P.J., Wainwright, T.C., Bryant, G.J., Lierheimer, L.J., Waples, R.S., Waknitz, F.W., and Lagomarsino, I.V. 1996. Status review of West Coast steelhead trout from Washington, Idaho, Oregon, and California. NOAA Technical Memorandum, NMFS-NWFSC, 27.

Coates, D.A., Hobson, W., McFadin, B., and Wilder, C. 2002. Mattole River watershed technical support document for the TMDLs for sediment and temperature: draft for public review. California Regional Water Quality Control Board, North Coast Region, Santa Rosa, Calif.

Cooper, E.J., O'Dowd, A.P., Graham, J.J., Mierau, D.W., Trush, W.J., and Taylor, R. 2020. Salmonid habitat and population capacity estimates for steelhead trout and Chinook salmon upstream of Scott Dam in the Eel River, California. Northwest Sci. 94(1): 70-96. doi:10.3955/046.094.0106.

Cordoleani, F., Phillis, C.C., Sturrock, A.M., FitzGerald, A.M., Malkassian, A., Whitman, G.E., et al. 2021. Threatened salmon rely on a rare life history strategy in a modified and warming landscape. Nat. Clim. Chang. 11: 982-988. doi:10.1038/s41558-021-01186-4

Cramer, S.P., and Ackerman, N.K. 2009a. Linking stream carrying capacity for salmonids to habitat features. In American Fisheries Society Symposium 71, pp. 225-254.

Cramer, S.P., and Ackerman, N.K. 2009b. Prediction of stream carrying capacity for steelhead trout: the unit characteristic method. In American Fisheries Society Symposium 71, pp. 255-288.

Cramer, S.P., and Beamesderfer, R.C.P. 2006. Population dynamics, habitat capacity, and a life history simulation model for steelhead trout in the Deschutes River, Oregon. Prepared for Portland General Electric, Portland, Oreg.

Cramer, S.P., Vaughan, J., Teply, M., and Duery, S. 2012. Potential gains in anadromous salmonid production from restoration of Beaver Creek (Sandy River Basin, Oregon). Army Corps of Engineers, Portland District, EC-6752, pp. 1-97.

Crozier, L.G., Burke, B.J., Chasco, B.E., Widener, D.L., and Zabel, R.W. 2021. Climate change threatens Chinook salmon throughout their life cycle. Commun. Biol. 4(1): 1-14. doi:10.1038/s42003-021-01734-w.

David, A.T., Asarian, J.E., and Lake, F.K. 2018. Wildfire smoke cools summer river and stream water temperatures. Water Resour. Res. 54(10): 7273-7290. doi:10.1029/2018WR022964.

Davies, J.R., Lagueux, K.M., Sanderson, B., and Beechie, T.J. 2007. Modeling stream channel characteristics from drainage-enforced DEMs in Puget Sound, Washington, USA. J. Am. Water Resour. Assoc. 43(2): 414-426. doi:10.1111/j.1752-1688. 2007.00032.x.

de la Hoz Franco, E.A., and Budy, P. 2005. Effects of biotic and abiotic factors on the distribution of trout and salmon along a longitudinal stream gradient. Environ. Biol. Fish. 72(4): 379-391. doi:10.1007/s10641-004-2591-4.

Eel River Forum. 2016. The Eel River Action Plan: A compilation of information and recommended actions. Eel River Forum.

Ewing, R.D., Johnson, S.L., Pribble, H.J., and Lichatowich, J.A. 1979. Temperature and photoperiod effects on gill $(\mathrm{Na}+\mathrm{K})$-ATPase activity in Chinook salmon (Oncorhynchus tshawytscha). J. Fish. Res. Bd. Can. 36(11): 1347-1353. doi:10.1139/f79-193.

Fausch, K.D., Hawkes, C.L., and Parsons, M.G. 1988. Models that predict standing crop of stream fish from habitat variables: 1950-85 (Vol. 213). US Department of Agriculture, Forest Service, Pacific Northwest Research Station.

Fausch, K.D., Nakano, S., and Ishigaki, K. 1994. Distribution of two congeneric charrs in streams of Hokkaido Island, Japan: considering multiple factors across scales. Oecologia, 100(1): 1-12. doi:10.1007/BF00317124.

FitzGerald, A., John, S., Apgar, T., and Martin, B. 2019. Quantification of thermal effects to improve temperature management of anadromous salmonids [poster]. Ecological Society of America, Louisville, Ky., USA, Unpublished conference paper.

FitzGerald, A.M., John, S.N., Apgar, T.M., Mantua, N.J., and Martin, B.T. 2021. Quantifying thermal exposure for migratory riverine species: phenology of Chinook salmon populations predicts thermal stress. Glob. Change Biol. 27: 536-549. doi:10.1111/gcb.15450.

Fraik, A.K., McMillan, J.R., Liermann, M., Bennett, T., McHenry, M.L., McKinney, G.J., et al. 2021. The impacts of dam construction and removal on the genetics of recovering steelhead (Oncorhynchus mykiss) populations across the Elwha River Watershed. Genes, 12(1): 89. doi:10.3390/genes12010089. PMID:33450806.

Flores, A.N., Bledsoe, B.P., Cuhaciyan, C.O., and Wohl, E.E. 2006. Channelreach morphology dependence on energy, scale, and hydroclimatic processes with implications for prediction using geospatial data. Water Resour. Res. 42(6): 1-15. doi:10.1029/2005WR004226.

Fullerton, A.H., Torgersen, C.E., Lawler, J.J., Steel, E.A., Ebersole, J.L., and Lee, S.Y. 2018. Longitudinal thermal heterogeneity in rivers and refugia for 
coldwater species: effects of scale and climate change. Aquat. Sci. 80(1): 3. doi:10.1007/s00027-017-0557-9.

Greene, C.M., Hall, J.E., Guilbault, K.R., and Quinn, T.P. 2010. Improved viability of populations with diverse life-history portfolios. Biol. Lett. 6: 382-386. doi:10.1098/rsbl.2009.0780. PMID:20007162.

Hilborn, R., Quinn, T.P., Schindler, D.E., and Rogers, D.E. 2003. Biocomplexity and fisheries sustainability. Proc. Natl. Acad. Sci. 100(11): 6564-6568. doi:10.1073/pnas.1037274100.

Hughes, N.F. 1998. A model of habitat selection by drift-feeding stream salmonids at different scales. Ecology, 79(1): 281-294. doi:10.1890/0012-9658 (1998)079[0281:AMOHSB]2.0.CO;2.

Isaak, D.J., Peterson, E.E., Ver Hoef, J.M., Wenger, S.J., Falke, J.A., Torgersen, C.E., et al. 2014. Applications of spatial statistical network models to stream data. Wiley Interdiscip. Rev. Water. 1(3): 277-294. doi:10.1002/wat2.1023.

Isaak, D.J., Wenger, S.J., Peterson, E.E., Ver Hoef, J.M., Nagel, D.E., Luce, C.H., et al. 2017. The NorWeST summer stream temperature model and scenarios for the western US: a crowd-sourced database and new geospatial tools foster a user community and predict broad climate warming of rivers and streams. Water Resour. Res. 53(11): 9181-9205. doi:10.1002/2017WR020969.

Jasiewicz, J., and Metz, M. 2011. A new GRASS GIS toolkit for Hortonian analysis of drainage networks. Comput. Geosci. 37(8): 1162-1173. doi:10.1016/j.cageo. 2011.03.003.

Johnson, S.L., Solazzi, M.F., and Rodgers, J.D. 1993. Development and evaluation of techniques to rehabilitate Oregon's wild salmonids. Oregon Department of Fish and Wildlife. Fish Research Project F-125-R, Annual Progress Report, Portland.

Kajtaniak, D., and Easterbrook, N. 2019. Sonar estimation of California Coastal (CC) Chinook salmon abundance in the Lower Mainstem Eel River, Humboldt County, California 2018/19. Lower Mainstem Eel River Coastal Chinook Monitoring Project Report, California Department of Fish and Wildlife.

Kannry, S.H., Thompson, S.A., O'Rourke, S.M., Harris, S.L., Kelson, S.J., and Miller, M.R. 2020. On the ecology and distribution of steelhead trout (Oncorhynchus mykiss) in California's Eel River. bioRxiv. doi:10.1101/2020.03.18. 996934.

Klein, R., Trush, W., and Buffleben, M. 2008. Watershed condition, turbidity, and implications for anadromous salmonids in north coastal California streams. Report to the California North Coast Regional Water Quality Board, Santa Rosa, California.

Kondolf, G.M., and Curry, R.R. 1986. Channel erosion along Carmel River, Monterey County, California. Earth Surf. Process. Landforms. 11: 307319I. doi:10.1002/esp.3290110308.

Larsen, D.A., Beckman, B.R., and Cooper, K.A. 2010. Examining the conflict between smolting and precocious male maturation in spring (streamtype) Chinook salmon. Trans. Am. Fish. Soc. 139(2): 564-578. doi:10.1577| T08-209.1.

Lindley, S.T., Schick, R.S., Agrawal, A., Goslin, M., Pearson, T.E., Mora, E., et al. 2006. Historical population structure of Central Valley steelhead trout and its alteration by dams. SFEWS. 4(1). doi:10.15447/sfews.2006v4iss1art3.

Lister, D.B., and Walker, C.E. 1966. The effect of flow control on freshwater survival of chum, coho, and Chinook salmon in the Big Qualicum River. Can. Fish Culturist. 37: 3-25.

Lorenzen, K. 1996. The relationship between body weight and natural mortality in juvenile and adult fish: a comparison of natural ecosystems and aquaculture. J. Fish Biol. 49(4): 627-642. doi:10.1111/j.1095-8649.1996.tb00060.x.

McEwan, D., and Jackson, T.A. 1996. Steelhead trout restoration and management plan for California. California Department of Fish and Game, Sacramento, Calif.

Marine, K.R., and Cech, J.J., Jr. 2004. Effects of high water temperature on growth, smoltification, and predator avoidance in juvenile Sacramento River Chinook salmon. N. Am. J. Fish. Manage. 24(1): 198-210. doi:10.1577/ M02-142.

McElhany, P., Rucklelshaus, M.H., Ford, M.J., Wainwright, T.C., and Bjorkstedt, E.P. 2000. Viable salmonid populations and the recovery of evolutionarily significant units. US Department of Commerce, NOAA, NMFS-NWFSC-42.

McMillan, J., Peters, R., McHenry, M., Brenkman, S., Morley, S., Pess, G., et al. 2019. The Elwha River: what have we learned since dam removal? Osprey, 93: 14-17.

Michel, C.J., Henderson, M.J., Loomis, C.M., Smith, J.M., Demetras, N.J., Iglesias, I.S., et al. 2020. Fish predation on a landscape scale. Ecosphere, 11(6): e03168. doi:10.1002/ecs2.3168.

Mohseni, O., and Stefan, H.G. 1999. Stream temperature/air temperature relationship: a physical interpretation. J. Hydrol. 218(3-4): 128-141. doi:10.1016/ S0022-1694(99)00034-7.

Montgomery, D.R., and Buffington, J.M. 1997. Channel-reach morphology in mountain drainage basins. Geol. Soc. Am. Bull. 109(5): 596-611. doi:10.1130/ 0016-7606(1997)109<0596:CRMIMD > 2.3.CO;2.

Montgomery, D.R., Beamer, E.M., Pess, G.R., and Quinn, T.P. 1999. Channel type and salmonid spawning distribution and abundance. Can. J. Fish. Aquat. Sci. 56(3): 377-387. doi:10.1139/f98-181.

Moyle, P., Lusardi, R., Samuel, P., and Katz, J. 2017. State of the Salmonids: status of California's Emblematic Fishes 2017. Center for Watershed Sciences, University of California, Davis and California Trout, San Francisco, Calif.
Myers, J.M., Kope, R.G., Bryant, G.J., Teel, D., Lierheimer, L.J., Wainwright, T.C., et al. 1998. Status review of Chinook salmon from Washington, Idaho, Oregon, and California. NOAA Technical Memorandum NMFS-NWFSC 35.

Nagel, D., Peterson, E., Isaak, D., Ver Hoef, J., and Horan, D., 2015. National Stream Internet protocol and user guide. US Forest Service, Rocky Mountain Research Station Air, Water, and Aquatic Environments Program. Available from http://www.fs.fed.us/rm/boise/AWAE/projects/NationalStreamInternet/ downloads/NationalStreamInternetProtocolandUserGuide.pdf.

Nakamoto, R.J. 1994. Characteristics of pools used by adult summer steelhead trout oversummering in the New River, California. Trans. Am. Fish. Soc. 123(5): 757-765. doi:10.1577/1548-8659(1994)123<0757:COPUBA > 2.3.CO;2.

Nakamoto, R.J., and Harvey, B.C. 2003. Spatial, seasonal, and size-dependent variation in the diet of Sacramento pikeminnow in the Eel River, northwestern California. Calif. Fish Game. 89(1): 30-45.

Nielsen, J.L., Lisle, T.E., and Ozaki, V. 1994. Thermally stratified pools and their use by steelhead trout in northern California streams. Trans. Am. Fish. Soc. 123(4): 613-626. doi:10.1577/1548-8659(1994)123<0613:TSPATU > 2.3.CO;2.

NMFS. 2002. Biological opinion for the proposed license amendment for the Potter Valley Project (Federal Energy Regulatory Commission Project Number 77-110). National Marine Fisheries Service.

NMFS. 2013. ESA Recovery Plan for Lower Columbia River Coho Salmon, Lower Columbia River Chinook salmon, Columbia River Chum Salmon, and Lower Columbia River Steelhead trout. US Dept of Commerce, National Oceanic Atmospheric Administration, National Marine Fisheries Service, Northwest Region, Seattle, Wash.

NMFS. 2016. Final Coastal Multispecies Recovery Plan for California Coastal Chinook salmon, Northern California Steelhead trout and Central California Coast Steelhead trout. US Dept of Commerce, National Oceanic Atmospheric Administration, National Marine Fisheries Service, Santa Rosa, Calif.

O'Dowd, A., and Trush, W. 2016. Friends of the Eel River Blockwater Investigation Final Memo. Humboldt State University River Institute.

Pess, G.R., McHenry, M.L., Beechie, T.J., and Davies, J. 2008. Biological impacts of the Elwha River dams and potential salmonid responses to dam removal. Northwest Sci. 82(sp1): 72-90. doi:10.3955/0029-344X-82.S.I.72.

Petersen, J.H., and Gadomski, D.M. 1994. Light-mediated predation by northern squawfish on juvenile chinook salmon. J. Fish Biol. 45: 227-242. doi:10.1111/ j.1095-8649.1994.tb01095.x.

Petersen, J.H., and Ward, D.L. 1999. Development and corroboration of a bioenergetics model for northern pikeminnow feeding on juvenile salmonids in the Columbia River. Trans. Am. Fish. Soc. 128(5): 784-801. doi:10.1577/15488659(1999) $128<0784$ :DACOAB $>2.0$.CO;2.

Peterson, E.E., and Ver Hoef, J.M. 2010. A mixed-model moving-average approach to geostatistical modeling in stream networks. Ecology, 91(3): 644-651. doi:10.1890/08-1668.1. PMID:20426324.

Pfeiffer, A.M., and Finnegan, N.J. 2017. Basin-scale methods for predicting salmonid spawning habitat via grain size and riffle spacing, tested in a California coastal drainage. Earth Surf. Process. Landforms. 42(6): 941-955. doi:10.1002/ esp.4053.

Puckett, L.K. 1975. The status of spring-run steelhead (Salmo gairdneri), of the Eel River system. Dep. of Wat. Res. and Dep. of Fish and Game, Memorandum Report.

PVP NOI Parties. 2020a. Potter Valley Project FERC Project No. 77: Initial Study Report. Potter Valley Project Notice of Intent Parties, Two-Basin Partnership Potter Valley. Available from https://www.twobasinsolution. org/reports/.

PVP NOI Parties. 2020b. Feasibility study report on potential licensing proposal for Potter Valley Project (FERC P. 77-285). Potter Valley Project Notice of Intent Parties, Two-Basin Partnership Potter Valley. Available from https://www.twobasinsolution.org/reports/.

Quinn, T.P. 2018. The behavior and ecology of Pacific salmon \& trout. 2nd ed. University of Washington Press, Seattle, Wash.

Railsback, S.F., and Rose, K.A. 1999. Bioenergetics modeling of stream trout growth: temperature and food consumption effects. Trans. Am. Fish. Soc. 128(2): 241-256. doi:10.1577/1548-8659(1999)128<0241:BMOSTG > 2.0.CO;2.

Rawding, D., Cooney, T., and Sharpe, C. 2010. Life history of tule fall Chinook salmon in lower Columbia River tributaries with estimates of juveniles survival, intrinsic productivity, and capacity from life cycle studies. National Marine Fisheries Service, Northwest Region, Portland, Oreg.

Reese, C.D., and Harvey, B.C. 2002. Temperature-dependent interactions between juvenile steelhead trout and Sacramento pikeminnow in laboratory streams. Trans. Am. Fish. Soc. 131(4): 599-606. doi:10.1577/1548-8659 (2002) $131<0599$ :TDIBJS $>2.0$.CO;2.

Rieman, B.E., Beamesderfer, R.C., Vigg, S., and Poe, T.P. 1991. Estimated loss of juvenile salmonids to predation by northern squawfish, walleyes, and smallmouth bass in John Day Reservoir, Columbia River. Trans. Am. Fish. Soc. 120(4): 448-458. doi:10.1577/1548-8659(1991)120<0448:ELOJST > 2.3.CO;2.

Rosenfeld, J. 2003. Assessing the habitat requirements of stream fishes: an overview and evaluation of different approaches. Trans. Am. Fish. Soc. 132(5): 953-968. doi:10.1577/T01-126.

Satterthwaite, W.H., Beakes, M.P., Collins, E.M., Swank, D.R., Merz, J.E., Titus, R.G., et al. 2010. State-dependent life history models in a changing (and regulated) environment: steelhead trout in the California Central Valley. Evol. Appl. 3(3): 221-243. doi:10.1111/j.1752-4571.2009.00103.x. PMID:25567921. 
Scheuerell, M.D., Hilborn, R., Ruckelshaus, M.H., Bartz, K.K., Lagueux, K.M., Haas, A.D., and Rawson, K. 2006. The Shiraz model: a tool for incorporating anthropogenic effects and fish-habitat relationships in conservation planning. Can. J. Fish. Aquat. Sci. 63(7): 1596-1607. doi:10.1139/ f06-056.

Sharron, S. 2015. Fish Out of Salt Water: Smoltification in Subyearling Chinook salmon from the Laurentian Great Lakes. University of Western Ontario - Electronic Thesis and Dissertation Repository, Paper 2715.

Spence, B.C., Bjorkstedt, E.P., Garza, J.C., Smith, J.J., Hankin, D.G., Fuller, D., et al. 2008. A framework for assessing the viability of threatened and endangered salmon and steelhead trout in the North-Central California Coast Recovery Domain. NOAA Technical Memorandum, SWFSC-423.

Stillwater Sciences, McBain Associates, McMillen Jacobs Associates, Cubed, M., Princeton Hydro, \& Geosyntec Consultants. 2021. Potter Valley Project Feasibility Study: Capital Improvements. Potter Valley Project Planning Agreement Parties. Available from https://www.twobasinsolution.org/reports/.

Sturrock, A.M., Carlson, S.M., Wikert, J.D., Heyne, T., Nusslé, S., Merz, J.E., et al. 2020. Unnatural selection of salmon life histories in a modified riverscape. Glob. Change Biol. 26(3): 1235-1247. doi:10.1111/gcb.14896.

Taniguchi, Y., Rahel, F.J., Novinger, D.C., and Gerow, K.G. 1998. Temperature mediation of competitive interactions among three fish species that replace each other along longitudinal stream gradients. Can. J. Fish. Aquat. Sci. 55(8): 1894-1901. doi:10.1139/f98-072.
US Office of the Federal Register. 1999. Endangered and threatened species: threatened status for two Chinook salmon evolutionarily significant units (ESUs) in California. Fed. Regist. 64: 50394-50415.

US Office of the Federal Register. 2000. Endangered and threatened species: Threatened Status for one steelhead trout evolutionarily significant unit (ESU) in California. Fed. Regist. 65: 36074-36094.

Ver Hoef, J.M., and Peterson, E.E. 2010. A moving average approach for spatial statistical models of stream networks. J. Am. Stat. Assoc. 105: 6-18. doi:10.1198/jasa.2009.ap08248.

Vigg, S., and Burley, C.C. 1991. Temperature-dependent maximum daily consumption of juvenile salmonids by northern squawfish (Ptychocheilus oregonensis) from the Columbia River. Can. J. Fish. Aquat. Sci. 48(12): 2491-2498. doi:10. 1139/f91-290.

VTN. 1982. Potter Valley Project (FERC Project Number 77-110) Fisheries Study: Final report volumes I and II. Venture Tech Network, Pacific Gas and Electric Company, San Ramon, Calif.

Williams, A.P., Cook, E.R., Smerdon, J.E., Cook, B.I., Abatzoglou, J.T, Bolles, K. et al. 2020. Large contribution from anthropogenic warming to an emerging North American megadrought. Science, 368(6488): 314-318. doi:10.1126/science. aaz9600. PMID:32299953.

Zeug, S.C., Bergman, P.S., Cavallo, B.J., and Jones, K.S. 2012. Application of a life cycle simulation model to evaluate impacts of water management and conservation actions on an endangered population of Chinook salmon. Environ. Model. Assess. 17(5): 455-467. doi:10.1007/s10666-012-9306-6. 